\title{
Neural Acupuncture Unit: A New Concept for Interpreting Effects and Mechanisms of Acupuncture
}

\author{
Zhang-Jin Zhang, ${ }^{1}$ Xiao-Min Wang, ${ }^{2}$ and Grainne M. McAlonan ${ }^{3}$ \\ ${ }^{1}$ School of Chinese Medicine, LKS Faculty of Medicine, The University of Hong Kong, 10 Sassoon Road, Pokfulam, Hong Kong \\ ${ }^{2}$ National Institute of Nursing Research, National Institutes of Health, Bethesda, MD 20892, USA \\ ${ }^{3}$ Department of Forensic and Neurodevelopmental Science, Institute of Psychiatry, King's College London, London, UK
}

Correspondence should be addressed to Zhang-Jin Zhang, zhangzj@hku.hk

Received 24 September 2011; Revised 30 November 2011; Accepted 1 December 2011

Academic Editor: Toku Takahashi

Copyright ( 92012 Zhang-Jin Zhang et al. This is an open access article distributed under the Creative Commons Attribution License, which permits unrestricted use, distribution, and reproduction in any medium, provided the original work is properly cited.

\begin{abstract}
When an acupuncture needle is inserted into a designated point on the body and mechanical or electrical stimulation is delivered, various neural and neuroactive components are activated. The collection of the activated neural and neuroactive components distributed in the skin, muscle, and connective tissues surrounding the inserted needle is defined as a neural acupuncture unit (NAU). The traditionally defined acupoints represent an anatomical landmark system that indicates local sites where NAUs may contain relatively dense and concentrated neural and neuroactive components, upon which acupuncture stimulation would elicit a more efficient therapeutic response. The NAU-based local mechanisms of biochemical and biophysical reactions play an important role in acupuncture-induced analgesia. Different properties of NAUs are associated with different components of needling sensation. There exist several central pathways to convey NAU-induced acupuncture signals, Electroacupuncture (EA) frequency-specific neurochemical effects are related to different peripheral and central pathways transmitting afferent signals from different frequency of NAU stimulation. More widespread and intense neuroimaging responses of brain regions to acupuncture may be a consequence of more efficient NAU stimulation modes. The introduction of the conception of NAU provides a new theoretical approach to interpreting effects and mechanisms of acupuncture in modern biomedical knowledge framework.
\end{abstract}

\section{Introduction}

Modern acupuncture can be defined as a therapeutic technique in which sharp, thin needles are inserted into specific points on the body with mechanical, electrical, or other physical stimulation. The nomenclature and localization of most specific points, known as acupuncture points or acupoints, were established in traditional Chinese medicine (TCM) during about B.C. 400-A.D. 1740s. Over the past four decades, numerous clinical observations and studies have shown that acupuncture therapy possesses broad therapeutic benefits $[1,2]$. A large body of experimental evidence obtained in animals and human subjects provides many insights into neural mechanisms of acupuncture effects, in particular acupuncture analgesia [3]. Today, this ancient healing technique is increasingly introduced into clinical practice, particularly for neuropsychiatric disorders [2]. Despite this, several fundamental issues remain unresolved in acupuncture research.

1.1. Metaphysical Concepts of Acupoint and Meridian in TCM. The doctrine of TCM was originally developed from elementary anatomical knowledge obtained in early days [4]. This is evidenced in numerous gross anatomical studies with measurement and a vast number of anatomical terms recorded in ancient TCM bibliographies. Ancient doctors had observed peripheral nerve trunks, branches, and plexus widely distributed in the superficial and deep tissues as well as on visceral organs, referring to as "meridians" and "collaterals" (Jing and Luo in Chinese). They believed that the meridians with the collaterals constitute an extensive network that communicates all parts of the body via the meridian energy (Jing-Q $i$ in Chinese). The meridian energy 
can flow onto specific loci, termed "convergences" or "conjunctions" in ancient terms and "acupoints" today. The doctrine of TCM clearly states that acupoints are not the skin, muscles, connective tissues, or bones, but local sites where the meridian energy effuses onto the superficial tissues and infuses into the deep tissues and visceral organs [4].

Ancient doctors also had observed that pathological conditions occurred in the deep tissues and visceral organs can be manifested as pain or tender points on the body, called A-Shi points. The localizations and clinical indications for most meridian-based acupoints were initially developed from A-Shi points. Ancient doctors suggested that stagnation of the meridian energy is a determining factor in the pathogenesis of diseases. Needling, moxibustion, and other forms of stimulation on acupoints were considered to improve pathological conditions by unblocking the stagnation of the meridian energy and rearranging the balance of Yin and Yang, that is, homeostasis.

It would seem that the metaphysical concepts of acupoint and meridian represent an entity with particular anatomical and physiological neural profiles. Nevertheless, how to precisely elucidate the metaphysical concepts of acupoint and meridian in the framework of modern biomedical knowledge has been a key issue in acupuncture research.

1.2. "Specific" and "Nonspecific" Properties of Acupoints. As acupoints are deemed "specific" points in the doctrine of TCM, many efforts have been made to identify their "specific" properties. Potential differences between the traditionally defined acupoints and so-called "nonacupoints" have been examined at anatomical, histological, biochemical, and electrophysiological levels in both animals and human subjects [4]. Although early studies indicate that most acupoints are located on or adjacent to peripheral nerve trunks or branches, and the meridians correspond with trajectories of relevant peripheral nerves [4], there is no convincing evidence to support the existence of novel or special structures beneath acupoints. However, histological studies indeed have revealed a relatively dense and concentrated distribution of certain neural and neuroactive components beneath many acupoints commonly used in clinical practice compared to adjacent areas [4]. Electrophysiological studies also have shown that the skin along with acupoints and meridians may possess distinct electrical properties which are closely associated with the activity of local neural and neuroactive components [5]. These results suggest the relativity of the "specific" and "nonspecific" properties of acupoints.

The definition and identification of the pattern of "specific" and "nonspecific" neural and neuroactive components in the response to acupuncture stimulation would help us better understand the essential mechanisms of acupuncture and develop more efficient acupuncture stimulation modes. However, the metaphysical concept of acupoint and meridian itself cannot provide sufficient information for defining and identifying the response pattern. Interactions between neural and neuroactive components as well as the relationship with the local and central response to acupuncture stimulation are also not well elucidated. Thus, it was necessary to introduce an alternative concept that substantially differentiates from the metaphysical concept of acupoint. Such concept would provide a more accurate term and a new theoretical approach to interpreting effects and mechanisms of acupuncture.

\section{The Definition of Neural Acupuncture Unit (NAU) and Its Differentiation from Acupoint}

Insertion into the skin with filiform needles is the most commonly used form of acupuncture stimulation in clinical practice. When a filiform needle is inserted into a designated point on the body and mechanical (manual manipulation) or electrical stimulation is delivered, a variety of neural and neuroactive components are activated. A collection of the activated neural and neuroactive components distributed in the skin, muscle, and connective tissues surrounding the inserted needle is defined as a neural acupuncture unit (NAU). Here, the designated points include not only the traditionally defined acupoints, which are often called as meridian-based acupoints or acupoints in short, but also A-Shi points and control points (sometimes called nonacupoints or placebo points) as specifically designated in acupuncture research.

Apparently, NAU is a hypothetical concept that represents local neural and neuroactive components in the physiological, biochemical, and therapeutic response to needling stimulation, rather than localization of the stimulation. On the other hand, viewed from ancient and modern anatomical perspective [4], the traditionally defined acupoints could be defined as an anatomical landmark system that indicates local sites where NAUs may contain relatively dense and concentrated neural and neuroactive components, upon which acupuncture stimulation would elicit a more efficient therapeutic response compared to nonacupoints. In theory, there are innumerable NAUs existing in the body as acupuncture procedure can be performed in different directions at the same point and on most areas of the body, including myriad A-Shi points and $361 \mathrm{WHO}$-defined standard acupoints [6]. The pattern of NAUs varies, mainly depending upon designated points and acupuncture stimulation mode as well as needling direction and depth. A hypothetical NAU is illustrated in Figure 1.

\section{Major Neural and Neuroactive Components of NAUs}

3.1. Neural Components. Early studies in animals and human autopsies revealed that most acupoints contained abundant free nerve endings, encapsulated cutaneous receptors (Merkel, Meissner, Ruffini, and Pacinian corpuscles), sarcous sensory receptors (muscle spindles and tendon organs), and their afferent fibers [4]. Somatic efferent fibers innervating muscles, small nerve bundles, and plexus were also observed in acupoint tissues, but no novel structures were found beneath acupoints. Many acupoints examined had relatively dense neural components, particularly nerves fibers, with a ratio of nearly $1.4: 1$ compared to non-acupoint areas [79]. The ratio of local myelinated to nonmyelinated fibers was 


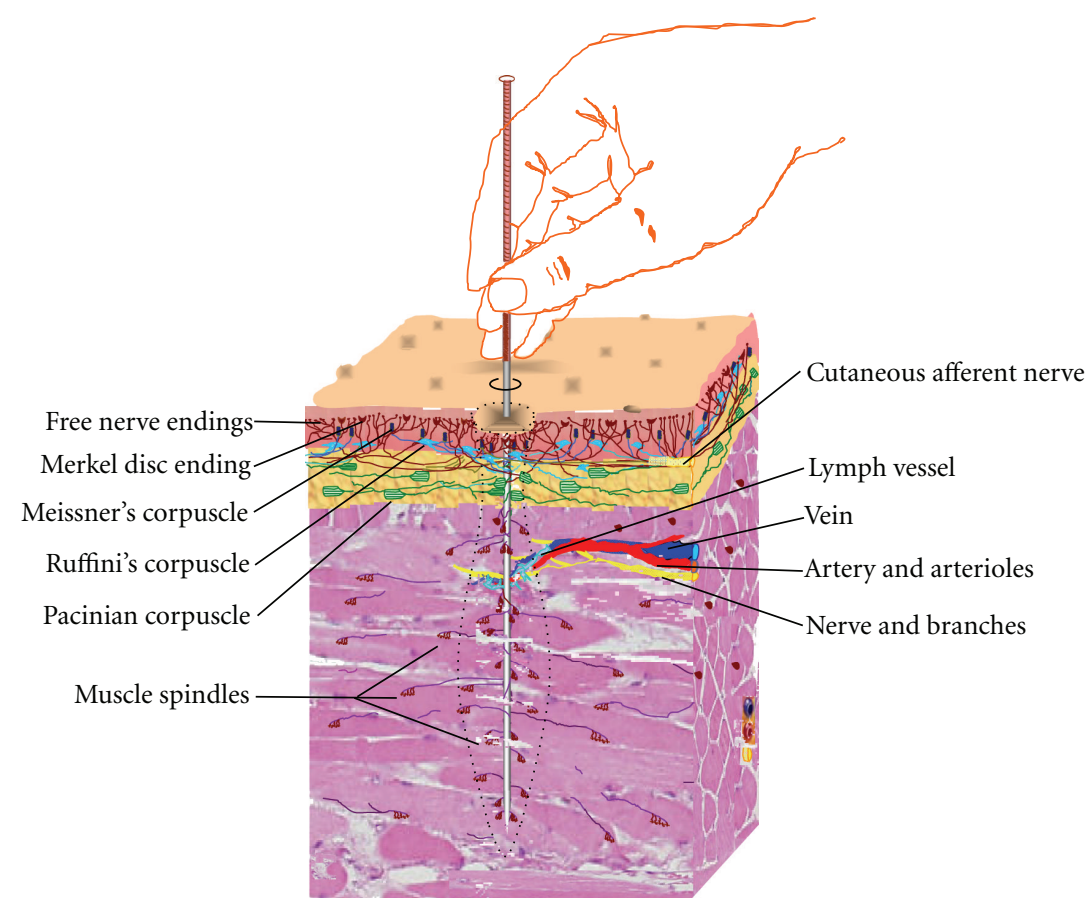

FIgURE 1: A representative muscle-spindle-rich NAU in the response to manual twists of acupuncture stimulation. The NAU with the related neural and neuroactive components is illustrated as the dotted line-defined vase-like pattern, which is principally determined by twistproduced different distant effects on mechanoreceptors located in cutaneous and muscle tissues (see Section 5.1).

found to be nearly 4-fold higher than surrounding areas in human Zu-San-Li (ST36) $[9,10]$. A similar phenomenon was also recorded in rats, showing that sarcous sensory receptors and their afferent fibers are concentrated at acupoints located on thick muscles [11].

Another important neural component of NAUs is dense and fine autonomic nerve fibers [12]. A close approximation of autonomic fiber varicosities and somatic afferent fiber terminals is often observed in rabbit acupoint areas [12]. Most autonomic nerves are noradrenaline- (NA-) containing sympathetic fibers, and an interaction between somatic and autonomic neural components may serve to modulate local and afferent signals in NAUs (see below).

3.2. Neuroactive Components and Related Mediators. Broadly speaking, neuroactive components of NAUs can be defined as nonneuronal tissues and cells that release various mediators capable of modulating afferent fiber transmission of NAUs. The most apparent neuroactive components are mast cells, sympathetic nerve-rich blood vessels, and small lymphatic vessels [4]. In addition to mast cells that release many neuroactive mediators, including histamine, substance $\mathrm{P}(\mathrm{SP})$, and other immune factors via a degranulation mechanism in response to acupuncture stimulation [13-15], other nonneuronal cells, including macrophages, fibroblasts, lymphocytes, platelets, and keratinocytes are also involved in the modulation of local and afferent signals of NAUs. These cells release various transmitters, modulators, inflammatory and immune factors, which directly or indirectly act at corresponding receptors on the surface of peripheral afferent fibers (see below). Table 1 summarizes major non-neuronal cell-released neuroactive mediators and their corresponding receptors. Based on their effects on afferent fiber excitability of NAUs, the mediators can be classified as inhibitory and stimulatory. The inhibitory mediators mainly include acetylcholine, noradrenaline (NA), $\gamma$-aminobutyric acid (GABA), $\beta$-endorphin, SP, somatostatin, nitric oxide (NO), ATP/cGMP, and adenosine, which suppress afferent fiber excitability of NAUs. Most cytokines, prostaglandins, bradykinin, and other proinflammatory factors are stimulatory mediators that directly or indirectly enhance afferent fiber excitability of NAUs. Serotonin (5-HT) and histamine can exert either inhibitory or stimulatory effects, depending upon which receptors they act on (Figure 2).

\section{Biochemical Reactions of NAUs}

When an acupuncture needle is inserted into a designated point and repetitively manipulated in different directions, it is assumed to cause local tissue injury and biochemical reactions, with the release of various inflammatory and immune mediators in NAUs. Nevertheless, unlike most other forms of tissue injury, acupuncture-induced tissue injury may represent a "positive" biochemical process resulting in therapeutic responses at local and systemic levels. This is considered due to a robust axon reflex and modulation of afferent fiber transmission in NAUs.

4.1. Acupuncture-Induced Robust Axon Reflex in NAUs. The axon reflex is a response to peripheral tissue injury, which 
TABLE 1: Major non-neuronal neuroactive mediators involved in the modulation of NAU afferent fiber excitability.

\begin{tabular}{|c|c|c|c|c|}
\hline Mediators & $\begin{array}{l}\text { Non-neuronal cells releasing neuroactive } \\
\text { mediators }\end{array}$ & $\begin{array}{l}\text { Receptors and actions on NAU } \\
\text { afferent fiber terminals }\end{array}$ & $\begin{array}{l}\text { Effects on NAU affer- } \\
\text { ent fiber excitability }\end{array}$ & Reference \\
\hline \multirow[t]{2}{*}{ Serotonin $(5-\mathrm{HT})$} & Platelets, mast cells & $5-\mathrm{HT}_{3}$ receptor & + & {$[17]$} \\
\hline & & $5-\mathrm{HT}_{1}$ receptor & - & {$[203]$} \\
\hline Noradrenaline (NA) & $\begin{array}{l}\text { Mainly released from sympathetic nerve } \\
\text { varicosities. Epidermal cells may be } \\
\text { NA-storing cells. }\end{array}$ & $\alpha_{2}$ Receptors & - & {$[51]$} \\
\hline Acetylcholine & $\begin{array}{l}\text { Keratinocytes and injured efferent fiber } \\
\text { terminals }\end{array}$ & Muscarinic $\mathrm{M}_{2}$ receptor & - & {$[204]$} \\
\hline \multirow[t]{2}{*}{ Histamine } & Mast cells & $\mathrm{H}_{3}$ receptor & - & {$[17]$} \\
\hline & & $\mathrm{H}_{1}$ receptor & + & \\
\hline Glutamate/aspartate & All skin epithelial cells and macrophage & Autoreceptors (?) & $-(?)$ & {$[35,36,205]$} \\
\hline $\begin{array}{l}\gamma \text {-aminobutyric acid } \\
(\mathrm{GABA})\end{array}$ & Macrophages and lymphocytes & $\mathrm{GABA}_{\mathrm{A}}$ receptors & - & {$[206,207]$} \\
\hline$\beta$-endorphin & $\begin{array}{l}\text { Keratinocytes, melanocytes, dermal } \\
\text { fibroblasts, and leukocytes }\end{array}$ & $\mu$-opiate receptors & - & {$[47,48,208]$} \\
\hline Substance P (SP) & $\begin{array}{l}\text { Mast cells, fibroblasts, platelets, } \\
\text { keratinocytes, and macrophages. }\end{array}$ & Autoreceptor (?) & $-(?)$ & {$[14,37,38,46]$} \\
\hline $\begin{array}{l}\text { Calcitonin } \\
\text { gene-related peptide } \\
\text { (CGRP) }\end{array}$ & Epithelial cells, T cells, macrophages & Autoreceptor (?) & $-(?)$ & {$[39,209,210]$} \\
\hline Somatostatin (SS) & Merkel cells, keratinocytes & SS receptors & - & {$[21,211-213]$} \\
\hline Nitric Oxide (NO) & Local tissues & $\begin{array}{l}\text { Inhibits SP release from primary } \\
\text { afferent terminals and enhances } \\
\text { acetylcholine and } \beta \text {-endorphin. }\end{array}$ & - & {$[50,214,215]$} \\
\hline ATP/cGMP & Epidermal cells & $\mathrm{P} 2 \mathrm{X}$ and $\mathrm{P} 2 \mathrm{Y}$ receptor & - & {$[31,214,216]$} \\
\hline Adenosine & $\begin{array}{l}\text { Degraded from ATP released in response to } \\
\text { mechanical, electrical, or heat stimulation. }\end{array}$ & $\mathrm{A}_{1}$ receptor & - & {$[31]$} \\
\hline Bradykinin & Local tissues and cells & $\mathrm{B}_{1 / 2}$ receptors & + & {$[217-219]$} \\
\hline $\begin{array}{l}\text { Cytokines (IL-1 } \beta \text {, } \\
\text { IL-6, IL- } 8 \text {, and } \\
\text { TNF- } \alpha \text { ) }\end{array}$ & Local tissues and cells & $\begin{array}{l}\text { Stimulate afferent fibers and } \\
\text { augment their excitability }\end{array}$ & + & {$[217-221]$} \\
\hline $\begin{array}{l}\text { Cytokines (IL-4 and } \\
\text { IL-10) }\end{array}$ & Local tissues and cells & $\begin{array}{l}\text { Inhibits the production of } \\
\text { inflammatory pain signals in } \\
\text { afferent terminals }\end{array}$ & - & {$[220,222]$} \\
\hline Prostaglandins & Local tissues and cells & EP receptors & + & {$[221,223]$} \\
\hline
\end{tabular}

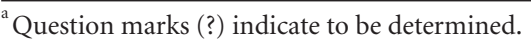

produces an impulse that moves from one nerve branch to other branches in close contact with nonneural tissues, mainly blood vessels, sweat glands, and mast cells [16]. This results in vasodilatation and release of vascular and neuroactive mediators from immune cells leaking from dilated vessels [17]. It is well documented that the axon reflex plays a central role in immune-nerve crosstalk, especially in neurogenic inflammation [17]. Clinical observations have demonstrated that acupuncture-induced axon reflex is strongly apparent in acupoint areas, particularly in the back and abdominal acupoints. It is characterized by a hyperemia (flare) that rapidly (generally within 2-5 min) spreads beyond needling points of the skin with a diameter of $1-3 \mathrm{~cm}$ (Figure 3(a)). Moreover, the acupuncture-evoked flare sometimes can spread along a meridian across several dermatomes supplied by nerves from totally different spinal segments, becoming a red line accompanied by the propagation of the needling sensation. This phenomenon is called the propagated sensation along meridians (PSM), which occurs in $0.3 \%$ of the healthy population [18].

The robust axon reflex of NAUs and PSM observed during acupuncture stimulation may be closely related to dense sympathetic nerve-rich arterioles, lymphatic vessels, and mast cells as well as concentrated primary afferent fibers in NAUs $[4,19]$. The acupuncture-induced robust axon reflex is more likely due to transient vasodilatation and temporary neural communication between adjacent branches of nerves from different spinal segments via vascular and neural mediators released from neural and nonneuronal tissues (Figure 3(b)) [15, 20, 21]. Apparently, the robust axon 


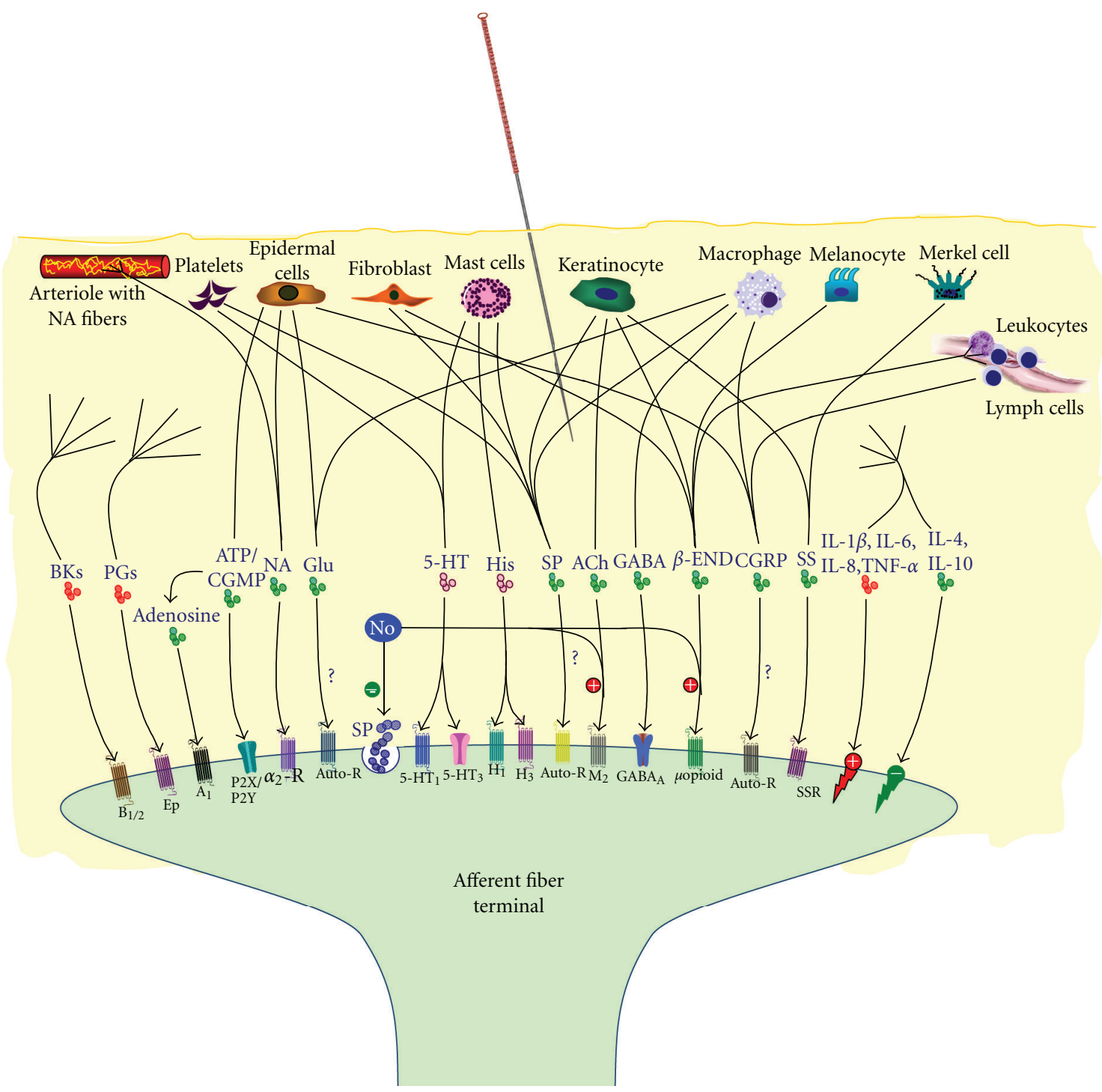

FIGURE 2: Schematic illustration of major nonneuronal neuroactive mediators and their corresponding receptors involved in the modulation of NAU afferent impulses. Molecules in red, green, and violet color represent stimulatory, inhibitory, and both effects on afferent fiber excitability, respectively. Autoreceptors to be identified are indicated with question symbols (?). $A_{1}$, adenosine $A_{1}$ receptor; $A C h$, acetylcholine; Auto-R, autoreceptor; $\mathrm{B}_{1 / 2}$, bradykinin receptors 1 and 2; BK, bradykinin; CGRP, calcitonin-gene-related peptide; $\beta$-END, $\beta$-endorphin; EP, prostaglandin E receptor; GABA, $\gamma$-aminobutyric acid; Glu, glutamate; $\mathrm{H}_{1} / \mathrm{H}_{2}$, histamine $\mathrm{H}_{1} / \mathrm{H}_{2}$ receptors; His, histamine; 5-HT, 5-hydroxytryptamine; IL, interleukin; $\mathrm{M}_{2}$, muscarinic $\mathrm{M}_{2}$ receptor; NA, noradrenaline; $\mathrm{NO}$, nitric oxide; PG, prostaglandins; P2X/P2Y, purinergic receptors $\mathrm{P} 2 \mathrm{X}$ and $\mathrm{P} 2 \mathrm{Y} ; \alpha_{2}-\mathrm{R}, \alpha_{2}$ adrenoceptor; SP, substance P; SS, somatostatin; SSR, somatostatin receptor; TNF- $\alpha$, tumor necrosis factor- $\alpha$.

reflex plays an important role in the production of local and afferent signals in NAUs [19].

4.2. Local Modulation of NAU Afferent Impulses by Neuroactive Mediators. In response to acupuncture-caused tissue injury, mast cells, platelets, and other immune cells migrate to make close contact with afferent nerve terminals in NAUs. The injured and migrated cells consequently release various neuroactive mediators, which infiltrate the tissues and act at corresponding receptors on the surface of afferent nerve terminals in NAUs via the axon reflex [17]. Meanwhile, tissue injury results in plastic changes in peripheral primary afferents, which develop synapse-like contacts with postganglionic sympathetic nerve varicosities, where NA release acts on $\alpha$-adrenoceptors on afferent nerve terminals of NAUs $[22,23]$.

Although acupuncture-caused tissue injury could induce the release of both inhibitory and stimulatory mediators from non-neuronal cells in NAUs via the robust axon reflex, as shown in Table 1, inhibitory mediators released may predominate over stimulatory mediators. Several lines of evidence indicate that the predominant effect of acupuncture is to enhance the activity of inhibitory mediators under pain conditions. First, compared to most other tissue injuries, 


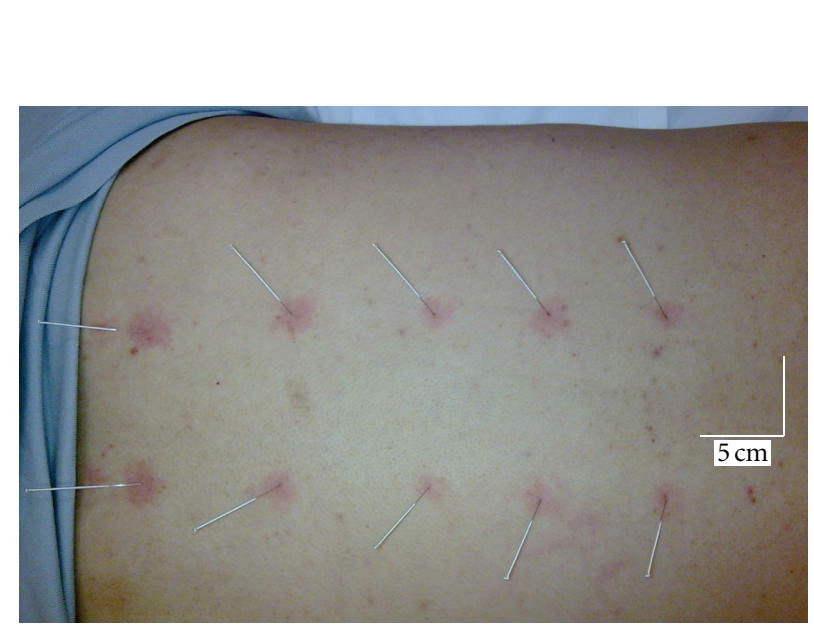

(a)

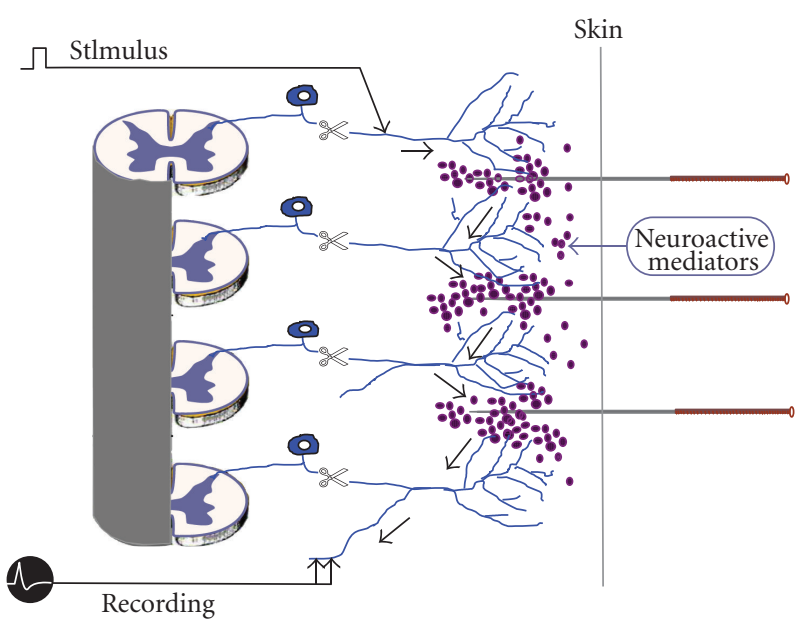

(b)

FIGURE 3: Acupuncture-induced robust axon reflex (a) and its involvement in the propagated sensation along meridians (PSM) (b). In (a), hyperemia (flare) was induced by acupuncture needling in acupoint areas of Bladder Meridian Foot Taiyang in the back. (b) illustrates putative communication between adjacent branches of nerves from different spinal segments via neuroactive mediators released by acupuncture stimulation from neural and non-neuronal tissues. (b) was reproduced based on the work done by Professor Zhao's research group with his generous permission (also see [20,21, 224]).

acupuncture-caused tissue injury is minimal. This may mean that the release of proinflammatory factors, most of which enhance NAU afferent fiber excitability, is limited. On the other hand, a large number of studies have shown that acupuncture significantly elevates the concentrations of many non-neuronal cell-released neuroactive mediators in local tissues at acupoints, especially including NA [24-26], $\beta$-endorphin $[27,28]$, somatostatin [29], and acetylcholine (ACh) [30], all of which suppress afferent fiber excitability of NAUs. Second, it is generally accepted that acupuncture is not only a noxious stimulus but is also mechanical and can be electrical (see below). Many inhibitory mediators, such as ATP and its metabolite adenosine, are released in response to mechanical and electrical stimulation [31]. Acupuncture stimulation has been found to robustly increase the extracellular concentrations of ATP and adenosine in mice's acupoint tissues, while analgesic effects were elicited [31].

Lastly, it is well known that a majority of peripheral small-diameter afferent fibers of the spinal and cranial nerves use the excitatory amino acid glutamate (Glu) as a transmitter [32, 33]. Most Glu-containing afferent fibers cocontain one or more peptides. Substance P (SP) and calcitonin generelated peptide (CGRP) are the most common peptides that are colocalized in a majority of afferent fibers [34]. Many non-neuronal cells also synthesize and release Glu, SP, and CGRP as shown in Table 1. It has been proposed that peripheral afferent fibers bear autoreceptors for Glu $[35,36]$, SP $[37,38]$, and CGRP [39]. A number of studies in rats and humans have shown that electroacupuncture increased the quantity of CGRP [40-42] and SP [42-44] in peripheral tissues and in blood circulation, although the effects on local non-neuronal glutamate and other excitatory transmitters are unclear. The increased mediators in local tissues are believed to at least partly come from nonneuronal cells, accounting for nearly $50 \%$ of total levels of SP in rodent peripheral tissues $[45,46]$. The elevation of non-neuronal mediators activates the negative feedback mechanism by acting at corresponding autoreceptors and, in turn, suppresses afferent fiber excitability of NAUs.

Taken together, it can be assumed that, in addition to central mechanisms, NAU-based local mechanisms play an equally important role in acupuncture analgesia, via which afferent noxious signals from sites distal to needling points are blocked mostly by enhancing the activity of inhibitory mediators and activating the autoreceptor-based negative feedback in NAUs. There have been many studies proving the NAU-based local mechanism of acupuncture analgesia. A recent study found that, while manual acupuncture on rat $\mathrm{Zu}-\mathrm{San}-\mathrm{Li}$ (ST36) produced pronounced analgesic effects, it also enhanced the degranulation of mast cells in local acupoint tissues; however, the analgesic effects were completely abolished by local injection of disodium chromoglycate, an inhibitor of mast cell degranulation, indicating the involvement of mast cell-released mediators in acupuncture analgesia [15]. Local injection of naloxone, an opioid receptor antagonist, an antibody against $\beta$ endorphin, or corticotropin-releasing factor antagonist also eliminated analgesic potency of electroacupuncture (EA) in animal models of acute and chronic inflammatory pain [47, 48]. Likewise, subcutaneous acupoint injection of neostigmine, a cholinesterase inhibitor, significantly enhanced painrelieving effects of EA in rats [30]. These studies suggest that the local $\beta$-endorphin and ACh play a key role in the local mechanism of analgesic effects of acupuncture.

Most recently, it was found that, while acupuncture on mice's Zu-San-Li (ST36) significantly reduced chronic pain in the ipsilateral paw and increased the extracellular 
concentrations of ATP and adenosine in acupoint tissues, the local application of 2-chloro-N(6)-cyclopentyladenosine (CCPA), an adenosine $\mathrm{A}_{1}$ receptor agonist, replicated the analgesic effect of acupuncture. The local inhibition of enzymes involved in adenosine degradation also potentiated the acupuncture-elicited increase in adenosine, as well as its antinociceptive effect [31]. These data strongly suggest that acupuncture-released ATP and its metabolite adenosine in local acupoint tissues block pain impulses from sites distal to needling point.

4.3. The Relationship between NAUs and Electrodermal Properties of Acupoints. It is well documented that many immune mediators, in particular, local tissue-released NA, nitric oxide (NO), tumor-related factors, and mast cell-released histamine and 5-HT [15, 24, 49-52], are heavily involved in the determination of electrical properties of acupoints and meridians, namely, higher conductance, lower impedance, and higher capacitance compared to adjacent tissues [5]. Electrodermal measures have been shown to be significantly associated with clinical outcomes of acupuncture treatments in patients with chronic pelvic pain [53]. Acupuncture stimulation was found to change the human skin sympathetic nerve activity [54]. Normalization of skin electrical conductance at related acupoints has also been linked to therapeutic responses to acupuncture in subjects with heart stress [55], obesity [56], and acute joint injury [57]. These observations suggest that normalization of electrodermal properties at acupoints is perhaps associated with the modulation of neuroactive mediators in acupuncture stimulation. Whether electrodermal measures of acupoints could serve as a reliable and valid approach in detecting biochemical properties of NAUs deserves further investigation.

\section{Biophysical Reactions of NAUs}

As mentioned above, acupuncture is not only a noxious stimulus but can include mechanical and electrical stimulation. Thus, apart from biochemical reactions, acupuncture also elicits biophysical reactions in NAUs. Early studies in rabbits have examined the responses of different types of NAU mechanoreceptors to different manual techniques and intensities of electrical stimulation [58-62]. The studies have revealed that the activation of the mechanoreceptors is not necessarily limited surrounding needling point but also can spread to a distance from needling point and this is referred to as "distant effect." Moreover, there are high negative linear correlations between the number of the activated receptors and distance from needling point (see Figures 4 and 5). The distant effect is, therefore, a most important component of the biophysical reactions of NAUs.

5.1. Manual Acupuncture- (MA-) Induced Distant Effects. In acupuncture practice, manual manipulation is often performed on the inserted needles to enhance needling sensation and therapeutic responses. The most commonly used manual techniques include lift, thrust, twist, rotation, shake, scrape, and flick. Gentle and repetitive manipulation onto the inserted needle would be expected to produce mechanical pressure and tissue distortion that activate NAU mechanoreceptors located in the skin, muscle, and tendon tissues [5863]. This mechanical effect has been well confirmed in recent studies of both mice and human subjects $[64,65]$.

It is well documented that the distant effect is mainly achieved by shear force- and stress-induced tissue displacements during manual manipulation [63-65]. All types of manual techniques tested have yielded greater distant effects on sarcous stretch receptors than cutaneous mechanoreceptors; twist/rotation has the greatest distant effects on the cutaneous superficial and deep receptors as well as sarcous stretch receptors compared to other techniques in rabbits (Figure 4) $[58,59]$. The order of the distant effects of twist/ rotation is sarcous stretch receptors, cutaneous superficial mechanoreceptors, and deep pressure-detected receptors. Based on this order, the twist-associated muscle-spindle-rich NAUs can be proposed to be a vase-like pattern as illustrated in Figure 1.

All types of manual techniques tested can activate $\mathrm{A} \alpha$, $\beta$, and $\delta$ fibers of NAUs. Twist/rotation additionally excites C-fibers on most occasions, whereas other types of manual techniques seldom do so $[62,66]$.

5.2. Electroacupuncture- (EA-) Induced Distant Effects. Electroacupuncture (EA) stimulation produces the distant effects in exciting cutaneous mechanoreceptors and sarcous stretch receptors of NAUs, with a range of nearly $25-45 \mathrm{~mm}$ from needling point. The EA intensity-dependent distant effect was observed on only the cutaneous superficial receptors, but not the cutaneous deep receptors and sarcous stretch receptors in rabbits (Figure 5) $[60,61]$.

Collectively, while most nociceptors are innervated by thin myelinated $\mathrm{A} \delta$ and $\mathrm{C}$ fibers, most somatic mechanoreceptors are innervated by $\mathrm{A} \beta$ fibers. Therefore, the activation of mechanoreceptors and their $\mathrm{A} \beta$ afferent fibers appears to play a dominant role in the biophysical reactions of NAUs, particularly in muscle-spindle-rich NAUs.

\section{NAU Classification and Its Differential Effects}

6.1. Classification of NAUs. It is well documented that somatosensory receptors and their afferent fibers play the central role in the production of NAU afferent impulses [3]. Based on the predominance of somatosensory receptors, NAUs can be roughly classified into the three types: muscle-spindlerich NAUs, cutaneous-receptor-rich NAUs, and tendonorgan-rich NAUs. Table 2 summarizes the definition, characteristics, and related acupoints of the three types of NAUs.

6.2. Differential Properties of Afferent Impulses Produced in Different Types of NAUs. It is generally accepted that NAU afferent impulses are initially produced through biochemical and biophysical reactions and transmitted dominantly by thin fibers (A $\delta$ and $C$ fibers) and thick fibers (A $\beta$ fibers), respectively. The impulses represent therapeutic information that mainly consists of both "positive" tissue injury-induced 


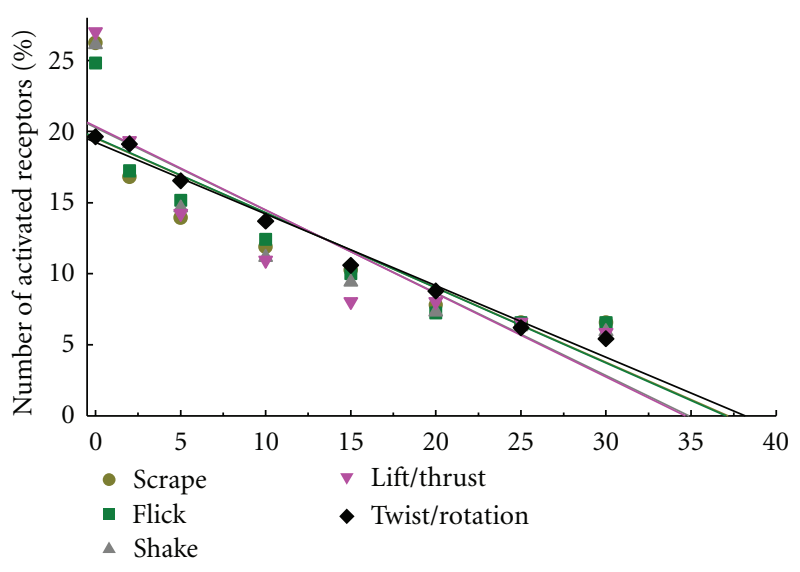

(a)

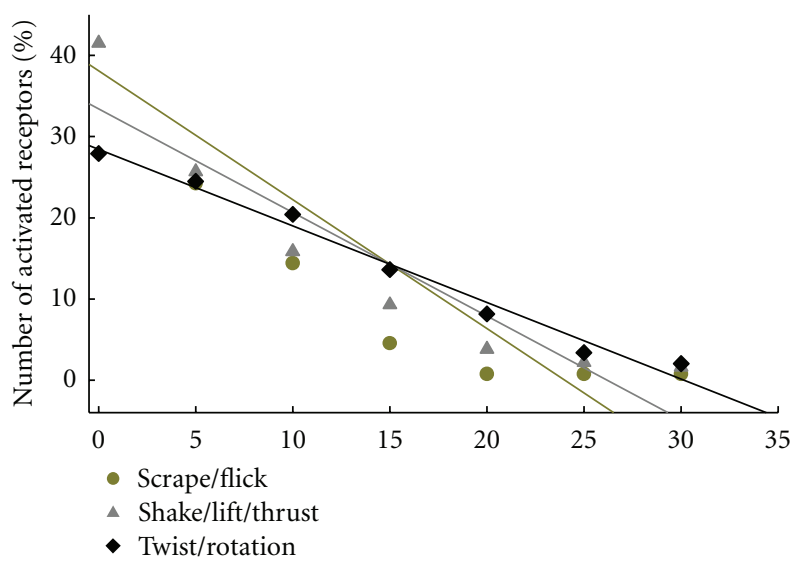

(b)

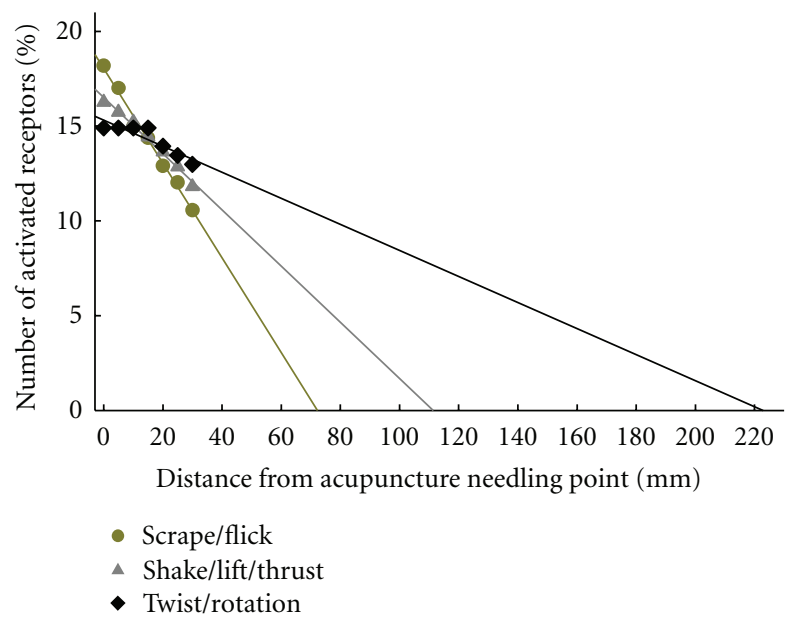

(c)

FIGURE 4: The distant effects of different manual techniques of acupuncture in activating cutaneous superficial mechanoreceptors (a), deep pressure-detected receptors (b), and muscle stretch receptors (c) located in the posterior aspect of the leg of Bladder Meridian Foot Taiyang in rabbits. Percent of the number of the activated receptors in each defined area surrounding needling point was calculated from the total number of the activated receptors. The plots were produced based on the data reported in $[58,59]$.

and mechanoreceptor-activated signals. However, the predominant components may vary, largely depending upon different types of NAUs. For most muscle-spindle- and tendon-organ-rich NAUs, the stretch receptor-activated signals dominate NAU afferent impulses. This assertion is supported by an early study on acupuncture analgesia in healthy volunteers, revealing that increased pain threshold produced by manual acupuncture at $\mathrm{He}-\mathrm{Gu}$ (LI4) was completely reversed by blockade of deep nerve branches innervating muscle fibers, but not cutaneous nerve branches [67]. Similar phenomena were also observed in acupuncture modulation of visceral functions in anesthetized rats, revealing that arterial blood pressure and heart rate were significantly reduced by manual acupuncture on acupoints with the muscles alone, but not the skin alone $[68,69]$. Likewise, bidirectional rotation of a needle deeply inserted into a muscle-spindle-rich NAU beneath the human acupoint Shou-San-Li (LI10) produced greater needle sensation intensities compared to superficial needle insertion with mock deep penetration and bidirectional rotation [70].
In contrast, for most cutaneous-receptor-rich NAUs, for example, Ren-Zhong (GV26) and Shi-Xuan (EX-UE11), which are often used as consciousness-awakening, spiritquieting, and mind-stabilizing acupoints for acute and severe neuropsychiatric conditions, such as summer stroke, shock, coma, acute fever-caused convulsion, trance, manic episode, and severe depression, the treatment effects are closely associated with patients' strong feeling of sharp pain evoked by pricking on the acupoints [71]. It appears that "positive" tissue injury-induced signals transmitted by small-diameter afferent fibers (mainly $\mathrm{A} \delta$ and $\mathrm{C}$ fibers) may dominate afferent impulses from cutaneous-receptor-rich NAUs.

6.3. The Relationship between NAU Properties and Components of Needling Sensation. A large body of empirical and experimental evidence confirms that acupuncture stimulation with and without accompanying needling sensation ( $D e-Q i$ in Chinese) leads to notable differences in neuroimaging [72, 73], electroencephalogram [74], and clinical 


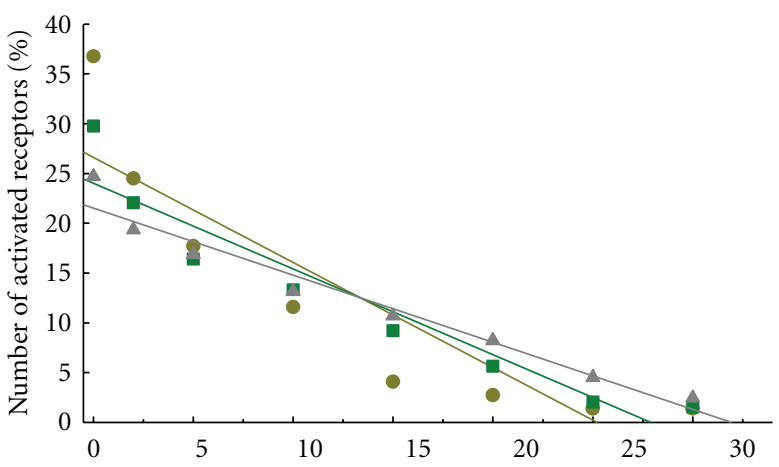

(a)

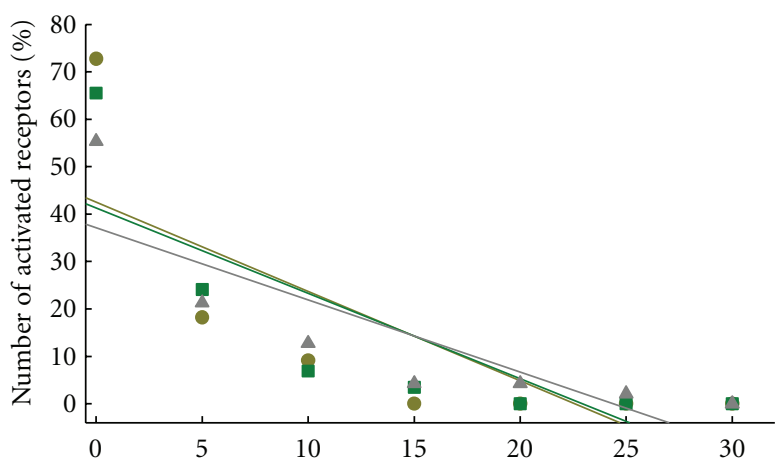

(b)

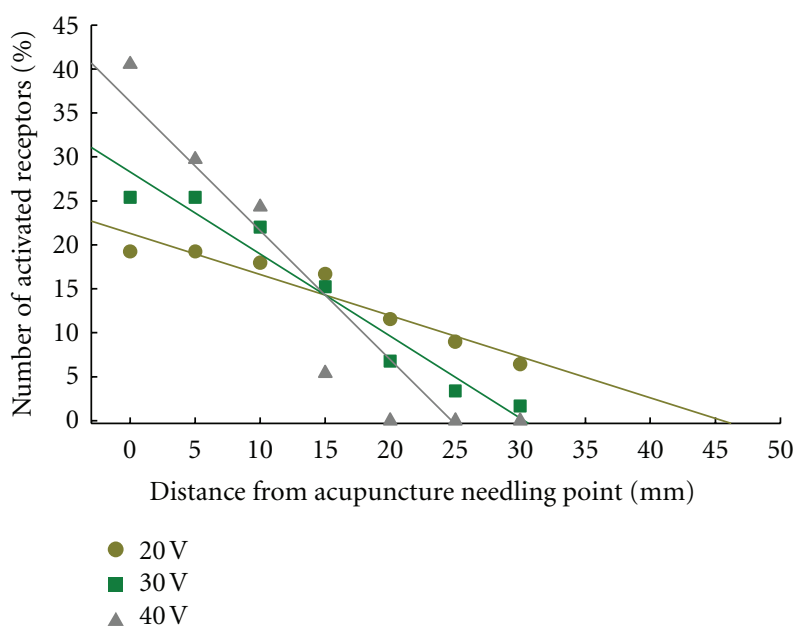

(c)

Figure 5: The distant effects of different intensities of electroacupuncture (EA) in activating cutaneous superficial mechanoreceptors (a), deep pressure-detected receptors (b), and muscle stretch receptors (c) located in rabbit triceps surae muscle areas of Bladder Meridian Foot Taiyang. Percent of the number of the activated receptors in each defined area surrounding needle point was calculated from the total number of the activated receptors. The plots were produced based on the data reported in $[60,61]$.

TABLE 2: Classification of NAUs based on a predominance of somatosensory receptors.

\begin{tabular}{|c|c|c|}
\hline Type & Definition and characteristics & Related acupoints \\
\hline $\begin{array}{l}\text { Muscle-spindle-rich } \\
\text { NAUs }\end{array}$ & $\begin{array}{l}\text { When an acupuncture needle is inserted, a large } \\
\text { portion of the inserted needle body is surrounded by } \\
\text { muscle fibers. Muscle spindles are the major neural } \\
\text { components in this type of NAUs. There are about } \\
210-2,860 \text { muscle spindles } / \mathrm{cm}^{3} \text { in muscle tissues in the } \\
\text { back of the Bladder-Meridian [225]. }\end{array}$ & $\begin{array}{l}\text { Nearly } 60 \% \text { acupoints located on thick muscle areas } \\
\text { contain this type of NAUs, for example, Zu-San-Li } \\
\text { (ST36), He-Gu (LI4), and Huan-Tiao (GB30). Most } \\
\text { acupoints can be performed with large-scale manual } \\
\text { techniques. }\end{array}$ \\
\hline $\begin{array}{l}\text { Cutaneous-receptor- } \\
\text { rich } \\
\text { NAUs }\end{array}$ & $\begin{array}{l}\text { Relatively dense and concentrated cutaneous receptors } \\
\text { dominate in NAUs. About } 100-240 \text { encapsulated } \\
\text { cutaneous receptors } / \mathrm{mm}^{2} \text { and } 300 \text { free nerve } \\
\text { endings } / \mathrm{mm}^{2} \text { are distributed in the cutaneous tissues of } \\
\text { the finger pads [226]. }\end{array}$ & $\begin{array}{l}\text { Most acupoints containing this type of NAUs are } \\
\text { located on the finger pads, palms, plantar areas, and the } \\
\text { surrounding of the lips, for example, Shao-Shang } \\
\text { (LU11), Lao-Gong (PC12), and Ren-Zhong (GV26). } \\
\text { Only prick and shallow needling can generally be } \\
\text { performed on these acupoints. }\end{array}$ \\
\hline $\begin{array}{l}\text { Tendon-organ-rich } \\
\text { NAUs }\end{array}$ & $\begin{array}{l}\text { Tendon organs, Ruffini and Pacinian corpuscles } \\
\text { dominate in NAUs. }\end{array}$ & $\begin{array}{l}\text { Most acupoints containing this type of NAUs are } \\
\text { located around the elbow, wrist, knee, and ankle joints, } \\
\text { for example, Chi-Ze (LU5), Da-Ling (PC7), Du-Bi } \\
\text { (ST35), and Jie-Xi (ST41). }\end{array}$ \\
\hline
\end{tabular}


TABLE 3: The putative relationship between NAU properties and needling sensation.

\begin{tabular}{|c|c|c|}
\hline \multirow{2}{*}{ NAU properties } & \multicolumn{2}{|c|}{ Components of needling sensation } \\
\hline & Aching/soreness/warmth & Numbness/heaviness/distension \\
\hline Type of NAUs & $\begin{array}{l}\text { Cutaneous-receptor-rich NAUs with a predominance } \\
\text { of nociceptors. }\end{array}$ & Muscle-spindle- and tendon-organ-rich NAUs. \\
\hline NAU reactions & Biochemical reaction & Biophysical reaction \\
\hline $\begin{array}{l}\text { Dominant afferent } \\
\text { fibers }\end{array}$ & $\mathrm{A} \delta$ and $\mathrm{C}$ & $\mathrm{A} \beta$ and $\mathrm{A} \delta$ \\
\hline $\begin{array}{l}\text { Acupuncture } \\
\text { stimulation modes }^{\mathrm{a}}\end{array}$ & $\begin{array}{l}\text { Prick; shallow needling; high-frequency EA; laser } \\
\text { acupuncture; heat acupuncture. }\end{array}$ & $\begin{array}{l}\text { Most manual techniques in gentle and repetitive manip- } \\
\text { ulation; low-frequency, high-intensity EA and TENS. }\end{array}$ \\
\hline
\end{tabular}

outcomes [75]. Needling sensation is, therefore, suggested to be a predictor for acupuncture analgesia [76]. Although the perception of needling sensation may vary in individuals and with manual techniques, this distinct sensation is generally characterized by soreness, numbness, heaviness, distension, and aching in the deep tissues surrounding the inserted needle [76], and often accompanies increased blood flow with a feeling of warmth at acupoint areas [77, 78]. The sensation also can be transmitted to the acupuncturist's fingers, which feel increased resistance to further movement of the inserted needle [79]. Thus, the needling sensation is not a single, but a compound sensation that is generated from the activation of various sensory receptors and their afferent fibers in NAUs, in particular, small fiber-innervated nociceptors and myelinated fiber-innervated mechanoreceptors, which, respectively, produce afferent impulses via biochemical and biophysical mechanisms of NAUs as described.

It is also well demonstrated that numbness, heaviness, and distension during needling are closely associated with the activation of myelinated $\mathrm{A} \beta$ and $\mathrm{A} \delta$ afferents in deep issues of acupoints, whereas aching and soreness are highly correlated with stimulation of small myelinated $\mathrm{A} \delta$ and unmyelinated $C$ fibers [10, 80-82]. Clinical practice also suggests that numbness, heaviness, and distension are more often elicited when manual manipulation is performed in muscle-spindle- and tendon-organ-rich NAUs, whereas the sensation evoked in cutaneous-receptor-rich NAUs is dominated by aching and soreness. The putative relationship between NAU properties and components of needling sensation is summarized in Table 3.

\section{Multiple Central Neural Pathways Conveying NAU Afferent Impulses}

As described above, acupuncture-evoked afferent impulses in most NAUs are mainly constituted by "positive" tissue injury-induced and mechanoreceptor-activated components. Neuroanatomically, there exist separate central pathways processing NAU afferent impulses from different components and from different parts of the body. Several spinal-supraspinal pathways responsible for acupuncture analgesia have been identified $[3,83]$. The trigeminal sensory pathway is involved in the transmission of NAU afferent impulses from the trigeminal territory [84]. Via these pathways, most NAU afferent signals are carried up to the brainstem, where the signals are relayed to other subcortical and cortical areas via direct projections and collateral branch connections. Major central neural pathways processing NAU afferent impulses are illustrated in Figure 6.

7.1. The Spinal-Supraspinal Pathways. The spinal-supraspinal pathways responsible for transmitting NAU afferent impulses from the territory innervated by the spinal nerves mainly comprise the spinothalamic tract, the spinoreticular tract, and the dorsal column-medial lemniscus tract. Most peripheral small afferent fibers bearing "positive" noxious signals from NAUs in the limbs, the trunk, and the neck terminate in the superficial layers of the spinal dorsal horn, where the signals are relayed and carried up by the contralateral spinothalamic tract to supraspinal levels [83]. Most peripheral thick myelinated afferent fibers bearing NAU mechanoreceptor-activated signals in the spinal nerve territory separately enter the ipsilateral dorsal columnmedial lemniscus tract and emerge into the contralateral spinothalamic tract. NAU impulses conveyed by the spinothalamic tract and the dorsal column are further relayed in the brainstem and the thalamus and ultimately sent to the somatosensory cortex in a somatotopic fashion [83]. Parallel to the somatotopic pathways, the spinoreticular tract receives NAU impulses largely via collateral connections with the somatotopic pathways at the spinal and supraspinal levels and diffusely projects to subcortical and cortical areas [83].

It is well documented that the spinothalamic and spinoreticular tracts are the two key ascending pathways, which convey NAU "positive" tissue injury-evoked signals and activate the descending noxious inhibitory system $[3,83]$. The latter mainly consists of the periaqueductal gray (PAG) nucleus raphe magnus (NRM) spinal pathway and the locus coeruleus (LC)-spinal pathway. These send inhibitory information to the spinal dorsal horn and block noxious signal inputs from the periphery $[3,83,85]$. In addition to receiving signals from the ascending pathways, the descending inhibitory system also receives wide afferent modulation 


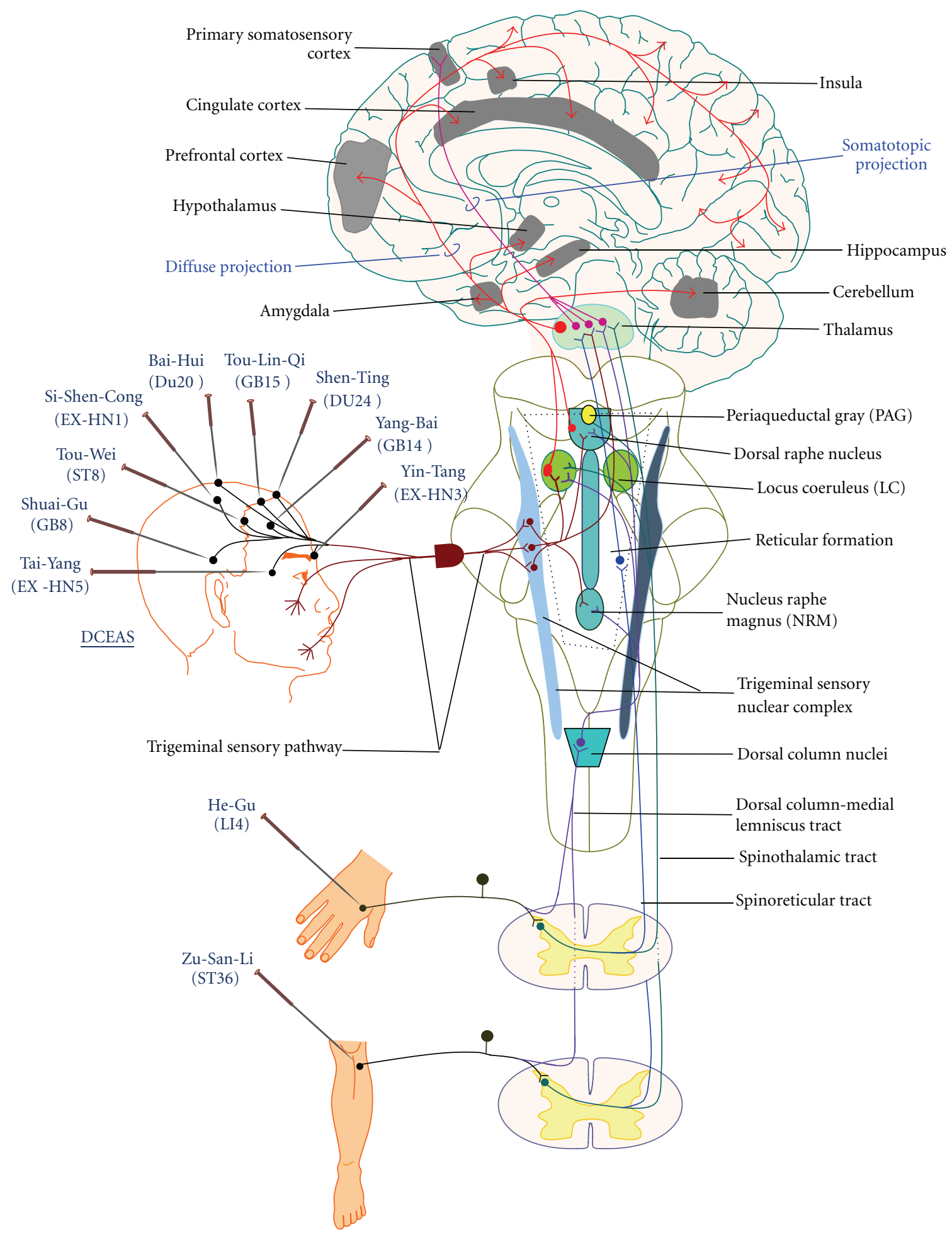

FIGURE 6: Schematic illustration of multiple central neural pathways transmitting NAU afferent impulses from different parts of the body. The brain areas commonly observed in neuroimaging response to acupuncture stimulation are indicated with gray shadow. DCEAS: dense cranial electroacupuncture stimulation. 
from supra-brainstem regions, including the hypothalamus, amygdala, prefrontal, anterior cingulated, and orbital cortex $[83,86]$.

As NAU mechanoreceptor-activated signals are believed to be the dominant components of afferent impulses in the majority of NAUs and the dorsal column-medial lemniscus tract receives multiple sources of sensory information, including cutaneous pain and visceral sensations in addition to fine touch and proprioception [87], it is thought that the dorsal column may play an equally important role in the processing of NAU afferent impulses. It has been shown that low-frequency EA stimulation (3 pulses/s) at acupoints in the rat hindlimbs increased neuronal nitric oxide synthase (NOs) expression in the gracile nucleus, an important relay of the rat dorsal column-medial lemniscus tract [88]. Repeated low-frequency EA stimulation of GuanYuan (CV4) in ovariectomized rats also enhanced the activity of neuronal cells in the cuneate nucleus, another important relay of the dorsal column [89]. However, cardiovascular responses induced by biphase-pulse electrical stimuli (3-30 pulses/s) at Zu-San-Li (ST36) were attenuated by blockade of neuronal conduction in the rat gracile nucleus [90]. These data suggest the involvement of the dorsal columnmedial lemniscus tract in the modulation of acupuncture effects, particularly in regulating visceral functions [91]. This is consistent with the central actions of transcutaneous electrical nerve stimulation (TENS), of which the activation of the dorsal column pathway is believed to be the principal mechanism [92].

7.2. The Trigeminal Sensory Pathway. Sensory information from the face and the forehead are principally conveyed inward by the trigeminal nerve to the brainstem trigeminal sensory nuclear complex [84]. While NAU afferent impulses in the trigeminal territory are transmitted to the somatosensory cortex, neuroanatomical studies suggest that, compared with the spinal-supraspinal pathways, the trigeminal sensory pathway has much closer connections with the brainstem reticular formation, particularly with the dorsal raphe nucleus (DRN) [93, 94] and the locus coeruleus (LC) [9598]. The latter two brain structures are the major resources of 5-HT and noradrenergic neuronal bodies, respectively, and play a pivotal role in the regulation of sensation, emotion, sleep, cognition, and visceral information processing [99, 100]. Furthermore, both low- and high-frequency EA stimulation has been reported to significantly increase the expression of 5-HT in the rat DRN [101-103] and suppress stress-induced increase in $c$-fos and tyrosine hydroxylase expression in LC $[85,104,105]$.

The closer connections between the trigeminal sensory pathway and the brainstem reticular formation, in particular serotonergic and catecholaminergic neuronal systems, provide an important neuroanatomical rationale for the utilization of an efficient stimulation modality called dense cranial electroacupuncture stimulation (DCEAS). In this technique, electrical stimulation of dense acupoints located on the forehead is expected to produce a robust therapeutic response (Figure 6). Several pilot studies have confirmed the efficacy of DCEAS in the treatment of headache [106], refractory obsessive-compulsive disorder (OCD) [107], major depression [108], poststroke depression [109], and vascular dementia [110]. Most recently, we further demonstrated the effectiveness of DCEAS as an additional therapy in enhancing the antidepressant response to fluoxetine, a selective 5-HT reuptake inhibitor in the early phase of the treatment of major depression [111].

\section{NAU-Associated Central Effects of Acupuncture}

8.1. The Widespread Brain Regional Response: Neuroimaging Evidence. Over the past two decades, thanks to technological advantages in the spatiotemporal mapping of regional brain functions, neuroimaging approaches, such as functional magnetic resonance imaging (fMRI) and positron emission topography (PET), have been widely introduced into acupuncture research. The initial aim of these studies is to identify brain regional and functional correlates of acupoints and acupuncture stimulation modes [112].

Although several studies have shown that acupuncture stimulation on acupoints traditionally used for the treatment of vision and hearing disorders are correlated with the activation of corresponding visual and auditory cortex, respectively [113-115], methodological heterogeneity and poor replication have raised the criticism that the response is caused by methodological flaws, rather than a direct result of specific effects of acupuncture $[116,117]$. In fact, apart from the somatotopic representation of acupoints in the primary somatosensory cortex, no well-defined correlations between distinct brain regional response patterns and a given acupoint or acupuncture stimulation mode have been identified. Instead, the vast majority of studies have consistently revealed that manual and electrical stimulation of single acupoints, represented by Zu-San-Li (ST36), He-Gu (LI4), Nei-Guan (PC6), Yang-Ling-Quan (GB34), Tai-Chong (LV3), Wai-Guan (TE5), and Guang-Ming (GB37), produces widespread modulation of cortical, limbic, subcortical, and brainstem areas through activation or deactivation in healthy volunteers [112]. Moreover, several brain regions display response patterns unrelated to acupoints and stimulation modes (Table 4). These brain structures are involved in diverse neurophysiological and psychological functions, including sensory, locomotor, visceral, sleep, emotion, and cognition processes. The widely distributed network constituted by these brain regions may, therefore, be essential substrates for the broader therapeutic effects of acupuncture. This widespread and diverse modulation of brain contingent upon acupuncture is most likely related to the multiple central pathways for the compound signal inputs that are initiated through the biochemical and biophysical reactions of NAUs.

Despite methodological issues of nonspecificity discussed above, numerous studies have indicated that manual and electrical stimulation at real acupoints modulate a greater extent of brain areas and elicit more intense response compared to control points or non-acupoints in healthy 
TABLE 4: Brain regions with common neuroimaging response to acupuncture stimulation and acupuncture-associated neurophysiological and psychological effects ${ }^{\mathrm{a}}$.

\begin{tabular}{lcl}
\hline Brain regions & $\begin{array}{c}\text { Functional neuroimaging } \\
\text { response to acupuncture }\end{array}$ & Acupuncture-associated effects \\
\hline $\begin{array}{l}\text { Primary somatosensory cortex } \\
\text { Prefrontal cortex }\end{array}$ & Activation & Pain and mechanoreceptor-activated signals \\
Insula & Activation & Cognition and emotion \\
Anterior cingulate cortex (ACC) & Activation/deactivation & Pain \\
Hypothalamus & Deactivation & Pain, attention, memory, and emotion \\
Amygdala/hippocampus & Activation & $\begin{array}{l}\text { Autonomic, neuroendocrine, visceral function, and stress- } \\
\text { processed center }\end{array}$ \\
Thalamus & Activation & $\begin{array}{l}\text { Encoding emotional signals and short-term memory } \\
\text { Pivotal relay station processing sensory inputs }\end{array}$ \\
$\begin{array}{l}\text { Cerebellum } \\
\text { Periaqueductal grey (PAG) and raphe } \\
\text { nuclei }\end{array}$ & Activation & $\begin{array}{l}\text { Activation } \\
\text { tional function }\end{array}$ \\
\hline
\end{tabular}

${ }^{a}$ Some contents were extracted from [112].

volunteers [118-124]. Similar results have been observed for manual acupuncture versus acupressure [125], deep versus shallow electrical stimulation on the same acupoints [126], rotating versus nonrotating stimulation [120], and long versus short duration of manual acupuncture [127]. Moreover, acupuncture-induced needling sensation without sharp pain also modulates greater extent of brain areas compared to needling sensation with sharp pain $[72,128]$. As acupointbased NAUs contain relatively dense neural and neuroactive components with the predominance and concentration of somatosensory receptors and their afferent innervations, stimulation modes with greater depth, longer duration, and accompanying needling sensation would be expected to activate more neural and neuroactive components and wider spectrum of afferent fibers, producing stronger and longerlasting NAU afferent signals. Therefore, more widespread and intense neuroimaging response appears to be a consequence of more efficient NAU stimulation.

\subsection{Frequency-Specific Neurochemical Response to Electroacu-} puncture (EA). It is well documented that many neurochemicals, in particular endogenous opiate peptides, 5-HT, and catecholamines, exhibit a frequency-dependent response in EA-produced analgesic effects $[3,129,130]$.

Analgesic effects produced by EA at human and animal acupoints with muscle spindle-rich NAUs, such as $\mathrm{Zu}-\mathrm{San}-\mathrm{Li}$ (ST36) and San-Yin-Jiao (SP6), are closely associated with enhanced release of endogenous opiate peptides in CNS [130]. Moreover, low-frequency $(2-15 \mathrm{~Hz})$ EA and TENS exert antinociceptive effects by enhancing the release of central enkephalin, endomorphin, $\beta$-endorphin, and dynorphin that act at $\mu$ - and $\delta$-receptors; whereas high frequency $(100 \mathrm{~Hz})$ produces antinociceptive effects by enhancing the release of dynorphin that mainly acts at $\kappa$-receptors [130].
Likewise, while both low- $(4-10 \mathrm{~Hz})$ and high- $(100 \mathrm{~Hz})$ frequency EA stimulation at Zu-San-Li (ST36) and HuanTiao (GB30) have been observed to produce a significant increase in immunoreactivity of 5-HT neuronal cells in the dorsal raphe nucleus and the nucleus raphe magnus, the high-frequency EA has more potent effects in increasing 5HT activity in the rat dorsal raphe nucleus compared to low frequency [101, 102, 131, 132]. Both frequencies have similar effects in enhancing the activity of catecholaminergic neurons in the rat hypothalamus and the brainstem reticular formation [103]. Stimulation with only $6,15,21 \mathrm{~Hz}$, but not 9, 12, 18, 24, 27, and $30 \mathrm{~Hz}$, at Da-Ling (PC7) has been found to significantly increase the release of dopamine in the rat striatum [130]. These studies clearly indicate frequencyspecific effects of EA in central neurochemical systems.

The frequency-specific neurochemical effects observed in acupuncture analgesia could be explained by different peripheral and central pathways transmitting NAU afferent signals produced by low- and high-frequency stimulation. It is well documented that low-frequency, high-intensity EA and TENS excite predominantly myelinated fibers $(\mathrm{A} \beta$ and $\mathrm{A} \delta$ ), whereas high-frequency EA mainly activates smalldiameter myelinated $\mathrm{A} \delta$ fibers and unmyelinated $\mathrm{C}$ fibers $[133,134]$. Neuroimaging studies have further demonstrated differences in brain regions modulated and the nature of modulation between $2 \mathrm{~Hz}$ and $100 \mathrm{~Hz}$ frequency stimulation on Zu-San-Li (ST36) and San-Yin-Jiao (SP6), although both frequencies elicit some common brain regional activity in human subjects $[135,136]$. The opioid gene expression pattern in the rat brain induced by $2 \mathrm{~Hz}$ is also different from $100 \mathrm{~Hz}$ [137]. These studies suggest that distinct central neurochemical response patterns are related to the differences in the predominant neural and neuroactive components of NAUs activated by low- and high-frequency stimulation. Based on the fact that high-frequency stimulation has more 
potent effects on 5-HT activity in the rat raphe nuclei [102, 131], it is likely that high-frequency-elicited NAU afferent impulses may be predominantly conveyed by the brainstem 5-HT neuronal system-relayed pathways.

8.3. The Normalizing Effects of Acupuncture in Pathological Conditions. Numerous clinical studies have revealed that acupuncture treatment is capable of reversing and even normalizing abnormal neuroimaging activity in patients with chronic pain [138-140], cerebral palsy [141], chronic stroke [142-145], Parkinson's disease [146], Alzheimer's disease [147], major depressive disorder [148, 149], and heroin addiction [150]. Moreover, most reversal and normalization of neuroimaging signals are correlated with clinical improvement.

Similar effects have been observed in normalizing neurochemical abnormalities in depressive conditions, showing that EA treatment protects against decreased 5-HT and catecholamine in depressed patients [151, 152] and in animal models of depression $[153,154]$. EA combined with antidepressant drugs even potentiates antidepressant effects in depressed patients $[155,156]$.

Consistent with this, both acute and repeated EA normalizes behavioral and biochemical abnormalities in various stressed animal models, including immobilization [105, 157163], maternal separation [164-166], chronic mild stress [167, 168], surgical trauma [169], chronic administration of corticosterone [160], cold stimulation [170], tooth-pulp stimulation [171], and mechanical colon distention [172].

Acupuncture therapy is also beneficial in treating visceral disorders, particularly functional gastrointestinal disorders $[173,174]$, heart rate variability [175], hypertension [176], urinary incontinence [177], and asthma [178]. It is well documented that the principal mechanism of visceral effects of acupuncture is to rearrange the balance of sympathetic and parasympathetic activity via somato-autonomic reflex $[129,179,180]$. NAU afferent signals are transmitted by multiple peripheral and central neural pathways to different levels in CNS, mainly the spinal cord, the brainstem, and the hypothalamus, where they are relayed to visceral organs via autonomic efferent fibers, neuroendocrine, and neuroimmune systems. This ultimately results in a rebalance of sympathetic and parasympathetic activity $[129,179,180]$.

Taken together, normalizing neuroimaging, neurochemical and behavioral abnormalities in neuropsychiatric conditions, as well as rebalancing sympathetic and parasympathetic activities in visceral disorders, represent broad therapeutic effects of acupuncture at systemic and central levels. These effects are achieved initially through an NAUbased local mechanism. There is an extensively bidirectional communication between the brain and peripheral immune system [181]. For instance, peripheral inflammatory information can be transmitted through peripheral sensory nerves to the visceral function-regulated brain regions, such as the solitary nucleus and the hypothalamus [182]. Changes in peripheral immune functions have been implicated in the etiology and pathogenesis of many neuropsychiatric syndromes [183-185]. Numerous studies confirm that such neuropsychiatry-associated peripheral immune changes are reflected in the subtle imbalance of immune mediators $[184,186]$. Pro- and anti-inflammatory factor imbalance in peripheral tissues has also been linked with various pain disorders [187-190], and imbalances of immune mediators have been widely observed in major depression [191, 192], anxiety disorders [191, 193], sleep disorders [194], and neuroendocrine disorders [195].

Acupuncture treatment has been shown to restore the balance between pro- and anti-inflammatory factors in depressed patients [192] and reestablish immunological balance in rats with experimental autoimmune encephalitis [196] and exposed to traumatic condition [197], while clinical symptoms and animal abnormal behavior were improved. It is, therefore, suggested that acupuncture stimulation improves central pathophysiology by rearranging the balance of peripheral neuroactive mediators and modulating NAU afferent signals. The ultimate result is the normalization of neuroimaging, neurochemical, and behavioral abnormalities and a rebalance of visceral autonomic activities. This explanation is consistent with the philosophy of TCM that an important mechanism of acupuncture effects is to rebuild the balance of Yin and Yang.

\section{Conclusions}

(1) NAU is a hypothetical concept that represents the collection of local neural and neuroactive components distributed in the skin, muscle, and connective tissues activated by an acupuncture needle that is inserted into a designated point on the body, and mechanical or electrical stimulation is delivered. The traditionally defined acupoints could be defined as an anatomical landmark system that indicates local sites where NAUs may contain relatively dense and concentrated neural and neuroactive components, upon which acupuncture stimulation would elicit a more efficiently physiological and therapeutic response compared to non-acupoints.

(2) Somatosensory receptors and their afferent fibers are the major neural components of NAUs and play the central role in the production of NAU afferent signals. Neuroactive components of NAUs are non-neuronal tissues and cells that release various mediators capable of modulating NAU afferent signals via local biochemical reactions. Biophysical reactions of NAUs are triggered by the activation of mechanoreceptors in NAUs due to mechanical pressure and tissue distortion induced during manual manipulation. NAUbased local mechanism plays an equally important role in acupuncture analgesia as central mechanisms.

(3) Different types of NAUs are associated with different NAU afferent impulses and components of needling sensation. The biochemical and biophysical reactions of NAUs dominantly activate small-diameter (A $\delta$ and $\mathrm{C}$ ) and myelinated afferent fibers $(\mathrm{A} \beta$ and $\mathrm{A} \delta)$, respectively. The induction of aching, soreness, and warmth of needling sensation are closely associated 
with the activation of $\mathrm{A} \delta$ and $\mathrm{C}$ fibers in NAUs, whereas numbness, heaviness, and distension are mainly related to the activation of $A \beta$ and $A \delta$ fibers.

(4) Multiple central neural pathways convey NAU afferent impulses. The spinothalamic and spinoreticular tracts dominantly transmit biochemical reactionevoked signals, whereas the dorsal column-medial lemniscus tract mainly transmits mechanoreceptoractivated signals. The trigeminal sensory pathway that conveys NAU afferent signals from the trigeminal territory has closer connections with the brainstem reticular formation, particularly 5 -HT and catecholaminergic neuronal systems, which play a pivotal role in the modulation of broad effects of acupuncture. DCEAS has superior effects in the treatment of neuropsychiatric disorders.

(5) A distributed network of widespread brain regions that respond to acupuncture provides the neural substrate for the broad therapeutic effects of acupuncture. The more widespread and intense brain regional response may be a consequence of more efficient NAU stimulation. A frequency-specific neurochemical response in the CNS may be related to differential response of NAUs to low- and highfrequency EA stimulation and different peripheral and central pathways. Acupuncture has broad effects of normalizing neuroimaging, neurochemical, and behavioral abnormalities in neuropsychiatric disorders as well as regulating autonomic activities in visceral disorders. These effects may be achieved initially by rearranging the subtle balance of neuroactive mediators and modulating NAU afferent impulses.

\section{Implications and Future Directions}

The establishment of the conception of NAU and its differentiation from acupoint not only provide an alternative theoretical approach into acupuncture research, but also bring many implications and impacts on further directions.

(1) The NAU-based local mechanism by which acupuncture stimulation locally modulates NAU biochemical reactions provides an important scientific rationale for traditional multiple-needling techniques, such as seven-star needling, plum-blossom-like needling, and round-needling, most of which are specifically used to treat focal lesions and pain conditions. The clarification of differences in local effects between multiple-needling and other needling techniques will help develop more efficient and specific acupuncture treatment regimens. Although the local roles of some NAU neuroactive mediators are well defined in acupuncture analgesia [15, 30,31, 47, 48], most NAU mediators, as listed in Table 1 , need to be further examined.

(2) While most previous studies have placed the emphasis on the lateral funiculus of the spinal cord; the dorsal column-medial lemniscus tract and the trigeminal sensory pathway have received relatively less attention. As mechanoreceptor-activated signals dominate in most NAU afferent impulses, particularly in muscle-spindle-rich and tendon-organ-rich NAUs, the role of the dorsal column-medial lemniscus tract in acupuncture effects deserves to be further clarified. As an efficient stimulation mode, DCEAS was developed based on the neuroanatomical rationale that NAUs in the trigeminal territory have intimate connections with the brainstem reticular formation. Neurophysiological and neuroimaging studies of this novel acupuncture mode will provide direct evidence to prove its efficiency.

(3) In clinical practice, acupuncture treatment regimens generally consist of multiacupoints located in different parts of the body. Empirical and experimental evidence suggests that the combination of local and distant acupoints produces greater treatment effects than the sum of single acupoints. Different central mechanisms are implicated in processing acupuncture signals from acupoints located in homeo- and heterosegmental spinal nerve territory [83]. Simultaneous stimulation of different acupoints appears to elicit more widespread and intense brain regional response [198]. Given that superior therapeutic response is associated with synergistic or additive effects of NAUs at local and systemic levels, the clarification of this relationship will provide valuable information in the development of more efficient acupuncture treatment regimens.

(4) Sham acupuncture often serves as a control in basic and clinical acupuncture research. The two most commonly used sham procedures are (i) insertion of acupuncture needles into control points generally defined at a certain distances (usually $1-3 \mathrm{~cm}$ ) from acupoints and (ii) noninserted placebo needling on the same acupoints [199]. These control procedures were initially designed to differentiate specific acupuncture effects at acupoints from non-acupoints. Nevertheless, as mentioned earlier, the most notable difference between most acupoints and nonacupoints is the relatively higher density of certain neural and neuroactive components with predominance and concentration of somatosensory receptors and their afferent fibers in acupoint-based NAUs. Clinically, it might be difficult to differentiate the effects of acupoints from adjacent points; even if needles are not inserted into the skin at nonacupoints, it may excite mechanoreceptors of NAUs. This could, at least in part, explain why most clinical studies have failed to demonstrate superior efficacy in "real" (or called "true", verum or genuine) acupuncture treatment regimens compared to sham or placebo regimens; sham acupuncture intervention even displays superior efficacy compared to inert placebo acupuncture $[1,200]$. In order to identify the systemic effects of acupuncture, a valid control design should completely block the production of NAU 
afferent impulses. For this purpose, the utilization of modified needles with local anesthetic drugs might be considered.

(5) Inadequate "dose" is thought to be an important factor in the failure of many clinical studies of acupuncture to achieve positive treatment outcomes [76]. Indeed, our recent meta-analysis of acupuncture therapy in depressive disorders [201] and a systematic review [202] have confirmed that most clinical trials did not include criteria for either qualitative or quantitative adequacy of acupuncture treatment regimens. Acupuncture "dosage" in fact represents both local and systemic efficiency of NAU stimulation. Local efficiency can be reflected in changes in local NAUassociated biochemical and electrodermal indices; systemic efficiency may be indicated in the needling sensation, neuroimaging, or neurochemical response recorded in CNS. While the verbal report of the intensity of needling sensation as a subjective scale has been demonstrated to be a valid psychological indicator for the intensity of acupuncture stimulation [203], the exploration of NAU-associated neurophysiological and neurochemical indicators may result in the discovery of objective measures of acupuncture "dosage."

\section{Acknowledgments}

This paper was derived from acupuncture research projects supported by Health and Health Services Research Fund (HHSRF) of Hong Kong Food and Health Bureau (Ref. no.: 06070831), General Research Fund (GRF) of Hong Kong Research Grant Council (RGC) (Ref. no.: 786611), and HKU intramural funds (Ref. no.: 10400876). The authors are grateful to Dr. Tun-Tak Ng and Ms. Kun Wai for their help in preparing illustrations, Professor Yan Zhao and Professor Yi Guo for kindly providing the original illustrations for Figure 3(b).

\section{References}

[1] K. Linde, A. Vickers, M. Hondras et al., "Systematic reviews of complementary therapies-an annotated bibliography. Part 1: acupuncture," BMC Complementary and Alternative Medicine, vol. 1, article 3, 2001.

[2] J. Park, K. Linde, E. Manheimer et al., "The status and future of acupuncture clinical research," The Journal of Alternative and Complementary Medicine, vol. 14, no. 7, pp. 871-881, 2008.

[3] Z. Q. Zhao, "Neural mechanism underlying acupuncture analgesia," Progress in Neurobiology, vol. 85, no. 4, pp. 355$375,2008$.

[4] F. Zhou, D. Huang, and Y. Xia, "Neuroanatomical basis of acupuncture points," in Acupuncture Therapy for Neurological Diseases: A Neurobiological View, Y. Xia, G. Wu, X. Cao et al., Eds., chapter 2, pp. 32-80, Tsinghua University Press, Beijing, China, 2010.

[5] A. C. Ahn, A. P. Colbert, B. J. Anderson et al., "Electrical properties of acupuncture points and meridians: a systematic review," Bioelectromagnetics, vol. 29, no. 4, pp. 245-256, 2008.
[6] S. Lim, "WHO standard acupuncture point locations," Evidence-Based Complementary and Alternative Medicine, vol. 7, no. 2, pp. 167-168, 2010.

[7] P. R. Hu and Z. Y. Zhao, "Regional anatomical study on major acupoints at triple energy meridian of Hand-Shaoyang," Jinzhou Medical College, no. 3, pp. 1-10, 1980.

[8] C. C. Han, "Acupuncture points histological properties," in Acupuncture: The Past and The Present, K. C. Huang, Ed., chapter 4, p. 47, Vontage Press, New York, NY, USA, 1996.

[9] G. W. Lu, R. Z. Liang, and J. Q. Xie, "Analysis of peripheral afferent fibers on effect of acupuncture analgesia at Zusanli point," Science in China, vol. 22, pp. 495-503, 1979.

[10] G. W. Lu, "Characteristics of afferent fiber innervation on acupuncture points zusanli," The American Journal of Physiology, vol. 245, no. 4, pp. R606-R612, 1983.

[11] A. H. Li, J. M. Zhang, and Y. K. Xie, "Human acupuncture points mapped in rats are associated with excitable muscle/ skin-nerve complexes with enriched nerve endings," Brain Research, vol. 1012, no. 1-2, pp. 154-159, 2004.

[12] Z. L. Tao, "The progress of the morphological research on the acupoint," Zhen Ci Yan Jiu, vol. 14, no. 4, pp. 397-402, 1989.

[13] D. D. Metcalfe, D. Baram, and Y. A. Mekori, "Mast cells," Physiological Reviews, vol. 77, no. 4, pp. 1033-1079, 1997.

[14] M. Toyoda, T. Makino, M. Kagoura, and M. Morohashi, "Immunolocalization of substance P in human skin mast cells," Archives of Dermatological Research, vol. 292, no. 8, pp. 418421, 2000.

[15] D. Zhang, G. Ding, X. Shen et al., "Role of mast cells in acupuncture effect: a pilot study," Explore, vol. 4, no. 3, pp. 170177, 2008.

[16] M. Yaprak, “The axon reflex," Neuroanatomy, vol. 7, pp. 1719, 2008.

[17] P. Holzer, "Neurogenic vasodilatation and plasma leakage in the skin," General Pharmacology, vol. 30, no. 1, pp. 5-11, 1998.

[18] G. J. Wang, M. H. Ayati, and W. B. Zhang, "Meridian studies in China: a systematic review," Journal of Acupuncture and Meridian Studies, vol. 3, no. 1, pp. 1-9, 2010.

[19] Y. Zhao, Q. X. Sun, S. H. Zhang et al., "Multiple neuropeptides participate in the peripheral information transmission across dermatomes," Zhen Ci Yan Jiu, vol. 27, no. 4, pp. 298302, 2002.

[20] D. Y. Cao, H. J. You, Y. Zhao et al., "Involvement of peripheral ionotropic glutamate receptors in activation of cutaneous branches of spinal dorsal rami following antidromic electrical stimulation of adjacent afferent nerves in rats," Brain Research Bulletin, vol. 72, no. 1, pp. 10-17, 2007.

[21] Y. Guo, F. R. Yao, D. Y. Cao et al., "Somatostatin inhibits activation of dorsal cutaneous primary afferents induced by antidromic stimulation of primary afferents from an adjacent thoracic segment in the rat," Brain Research, vol. 1229, pp. 61-71, 2008.

[22] W. Janig, J. D. Levine, and M. Michaelis, "Interactions of sympathetic and primary afferent neurons following nerve injury and tissue trauma," Progress in Brain Research, vol. 113, pp. 161-184, 1996.

[23] G. Rubin, T. Kaspi, Z. H. Rappaport et al., "Adrenosensitivity of injured afferent neurons does not require the presence of postganglionic sympathetic terminals," Pain, vol. 72, no. 1-2, pp. 183-191, 1997.

[24] J. X. Chen and S. X. Ma, "Effects of nitric oxide and noradrenergic function on skin electric resistance of acupoints and meridians," Journal of Alternative and Complementary Medicine, vol. 11, no. 3, pp. 423-431, 2005. 
[25] J. X. Chen, B. O. Ibe, and S. X. Ma, "Nitric oxide modulation of norepinephrine production in acupuncture points," Life Sciences, vol. 79, no. 23, pp. 2157-2164, 2006.

[26] A. Sato, Y. Sato, A. Suzuki, and S. Uchida, "Reflex modulation of catecholamine secretion and adrenal sympathetic nerve activity by acupuncture-like stimulation in anesthetized rat," The Japanese Journal of Physiology, vol. 46, no. 5, pp. 411-421, 1996.

[27] D. F. Bossut, L. S. Leshin, M. W. Stromberg, and P. V. Malven, "Plasma cortisol and beta-endorphin in horses subjected to electro-acupuncture for cutaneous analgesia," Peptides, vol. 4, no. 4, pp. 501-507, 1983.

[28] B. Y. Chen and J. Yu, "Relationship between blood radioimmunoreactive beta-endorphin and hand skin temperature during the electro-acupuncture induction of ovulation," Acupuncture and Electro-Therapeutics Research, vol. 16, no. 1-2, pp. 1-5, 1991.

[29] K. Uvnäs-Moberg, T. Lundeberg, G. Bruzelius et al., "Vagally mediated release of gastrin and cholecystokinin following sensory stimulation," Acta Physiologica Scandinavica, vol. 146, no. 3, pp. 349-356, 1992.

[30] X. Guan, X. Liang, and X. Liu, "Acetylcholine and the primary input of acupuncture sensation-influence of peripheral acetylcholine on the role of electroacupuncture analgesia," Zhen ci Yan Jiu, vol. 15, no. 2, pp. 136-139, 1990 (Chinese).

[31] N. Goldman, M. Chen, T. Fujita et al., "Adenosine A1 receptors mediate local anti-nociceptive effects of acupuncture," Nature Neuroscience, vol. 13, no. 7, pp. 883-888, 2010.

[32] S. De Biasi and A. Rustioni, "Glutamate and substance P coexist in primary afferent terminals in the superficial laminae of spinal cord," Proceedings of the National Academy of Sciences of the United States of America, vol. 85, no. 20, pp. 7820-7824, 1988.

[33] N. E. Lazarov, "Comparative analysis of the chemical neuroanatomy of the mammalian trigeminal ganglion and mesencephalic trigeminal nucleus," Progress in Neurobiology, vol. 66, no. 1, pp. 19-59, 2002.

[34] F. J. Diez Guerra, M. Zaidi, P. Bevis, I. MacIntyre, and P. C. Emson, "Evidence for release of calcitonin gene-related peptide and neurokinin A from sensory nerve endings in vivo," Neuroscience, vol. 25, no. 3, pp. 839-846, 1988.

[35] S. M. Carlton, G. L. Hargett, and E. Richard, "Localization and activation of glutamate receptors in unmyelinated axons of rat glabrous skin," Neuroscience Letters, vol. 197, no. 1, pp. 25-28, 1995.

[36] F. Karim, G. Bhave, and R. W. Gereau IIII, "Metabotropic glutamate receptors on peripheral sensory neuron terminals as targets for the development of novel analgesics," Molecular Psychiatry, vol. 6, no. 6, pp. 615-617, 2001.

[37] S. M. Carlton, S. Zhou, and R. E. Coggeshall, "Localization and activation of substance $\mathrm{P}$ receptors in unmyelinated axons of rat glabrous skin," Brain Research, vol. 734, no. 12, pp. 103-108, 1996.

[38] H. Z. Hu, Z. W. Li, and J. Q. Si, "Evidence for the existence of substance $\mathrm{P}$ autoreceptor in the membrane of rat dorsal root ganglion neurons," Neuroscience, vol. 77, no. 2, pp. 535-541, 1997.

[39] G. Segond von Banchet, A. Pastor, C. Biskup, C. Schlegel, K. Benndorf, and H. G. Schaible, "Localization of functional calcitonin gene-related peptide binding sites in a subpopulation of cultured dorsal root ganglion neurons," Neuroscience, vol. 110, no. 1, pp. 131-145, 2002.
[40] C. P. Carlsson, F. Sundler, and J. Wallengren, "Cutaneous innervation before and after one treatment period of acupuncture," British Journal of Dermatology, vol. 155, no. 5, pp. 970-976, 2006.

[41] Y. M. Jan, T. C. Li, and C. L. Hsieh, "A Segmental effect involved in the changes of skin blood flow induced by acupuncture in normal health human," The American Journal of Chinese Medicine, vol. 38, no. 3, pp. 441-448, 2010.

[42] H. Kashiba and Y. Ueda, "Acupuncture to the skin induces release of substance $\mathrm{P}$ and calcitonin gene-related peptide from peripheral terminals of primary sensory neurons in the rat," The American Journal of Chinese Medicine, vol. 19, no. 3-4, pp. 189-197, 1991.

[43] L. Q. Cao and T. Wang, "The change of the concentration of substance P in the rats "channel" "point" skin and plasma in the acupuncture analgesia," Zhen Ci Yan Jiu, vol. 14, no. 4, pp. 452-462, 1989.

[44] G. Jansen, T. Lundeberg, J. Kjartansson, and U. E. Samuelson, "Acupuncture and sensory neuropeptides increase cutaneous blood flow in rats," Neuroscience Letters, vol. 97, no. 3, pp. 305-309, 1989.

[45] N. Erin and G. A. Clawson, "Parameters affecting substance P measurement in heart, lung, and skin," BioTechniques, vol. 37, no. 2, pp. 232-239, 2004.

[46] N. Erin and O. Ulusoy, "Differentiation of neuronal from non-neuronal Substance P," Regulatory Peptides, vol. 152, no. 1-3, pp. 108-113, 2009.

[47] R. Sekido, K. Ishimaru, and M. Sakita, "Differences of electroacupuncture-induced analgesic effect in normal and inflammatory conditions in rats," The American Journal of Chinese Medicine, vol. 31, no. 6, pp. 955-965, 2003.

[48] G. G. Zhang, C. Yu, W. Lee, L. Lao, K. Ren, and B. M. Berman, "Involvement of peripheral opioid mechanisms in electroacupuncture analgesia," Explore, vol. 1, no. 5, pp. 365371, 2005.

[49] J. Y. Fan, Z. M. Wei, Z. Liu et al., "Effect of catecholamines on the skin conductance in mice," Journal of Beijing Medical University, vol. 25, pp. 324-326, 1993.

[50] S. X. Ma, "Enhanced nitric oxide concentrations and expression of nitric oxide synthase in acupuncture points/meridians," The Journal of Alternative and Complementary Medicine, vol. 9, no. 2, pp. 207-215, 2003.

[51] V. Ogay, S. K. Min, J. S. Hyo, J. C. Cheon, and K. S. Soh, "Catecholamine-storing cells at acupuncture points of rabbits," Journal of Acupuncture and Meridian Studies, vol. 1, no. 2, pp. 83-90, 2008.

[52] F. Wick, N. Wick, and M. C. Wick, "Morphological analysis of human acupuncture points through immunohistochemistry," American Journal of Physical Medicine and Rehabilitation, vol. 86, no. 1, pp. 7-11, 2007.

[53] A. C. Ahn, R. Schnyer, L. Conboy, M. R. Laufer, and P. M. Wayne, "Electrodermal measures of jing-well points and their clinical relevance in endometriosis-related chronic pelvic pain," Journal of Alternative and Complementary Medicine, vol. 15, no. 12, pp. 1293-1305, 2009.

[54] S. Knardahl, M. Elam, B. Olausson, and B. G. Wallin, "Sympathetic nerve activity after acupuncture in humans," Pain, vol. 75, no. 1, pp. 19-25, 1998.

[55] C. C. Hsu, C. S. Weng, T. S. Liu, Y. S. Tsai, and Y. H. Chang, "Effects of electrical acupuncture on acupoint BL15 evaluated in terms of heart rate variability, pulse rate variability and skin conductance response," The American Journal of Chinese Medicine, vol. 34, no. 1, pp. 23-36, 2006. 
[56] C. S. Weng, Y. L. Hung, L. Y. Shyu, and Y. H. Chang, "A study of electrical conductance of meridian in the obese during weight reduction," The American Journal of Chinese Medicine, vol. 32, no. 3, pp. 417-425, 2004.

[57] J. F. Zhang, B. Y. Deng, and S. Y. Su, "Analysis on the channel state in 45 patients with acute sport injury of external malleolus joint," Zhen Ci Yan Jiu, vol. 32, no. 1, pp. 62-66, 2007.

[58] Q. Dong, X. Dong, D. Chen, H. Li, and S. Zhang, "The relation between acupuncture manipulations and responsive discharges of cutaneous receptors," Zhen Ci Yan Jiu, vol. 17, no. 3, pp. 221-229, 1992.

[59] Q. Dong, X. Dong, D. Chen, H. Li, and M. Xian, “The relations between acupuncture manipulations and responsive discharges of deep receptors," Zhen ci yan jiu = Acupuncture research / [Zhongguo yi xue ke xue yuan Yi xue qing bao yan jiu suo bian ji], vol. 18, no. 1, pp. 75-82, 1993.

[60] Q. Dong, X. Dong, H. Li et al., "The influence of electroacupuncture on the activity of deep body receptors," Shanghai Journal of Acupuncture, vol. 21, pp. 38-40, 2002.

[61] Q. Dong, X. Dong, H. Li et al., "The influence of electroacupuncture on the activity of cutaneous receptors," Journal of Sichuan of Traditional Chinese Medicine, vol. 20, pp. 9-11, 2002.

[62] X. Dong and Q. Dong, "The relations between acupuncture manipulations and types of afferent fibers," Shanghai Journal of Acupuncture, vol. 8, pp. 23-27, 1988.

[63] Y. Zhao, W. C. Shi, and Z. L. Hou, "The effect of acupuncture manipulation to the discharges of needling sensation receptors," Zhen Ci Yan Jiu, vol. 13, no. 3, pp. 221-225, 1988.

[64] H. M. Langevin, E. E. Konofagou, G. J. Badger et al., "Tissue displacements during acupuncture using ultrasound elastography techniques," Ultrasound in Medicine and Biology, vol. 30, no. 9, pp. 1173-1183, 2004.

[65] G. Li, J. M. Liang, P. W. Li et al., "Physiology and cell biology of acupuncture observed in calcium signaling activated by acoustic shear wave," Pflügers Archiv, vol. 462, no. 4, pp. 587597, 2011.

[66] F. Kagitani, S. Uchida, H. Hotta, and Y. Aikawa, "Manual acupuncture needle stimulation of the rat hindlimb activates groups I, II, III and IV single afferent nerve fibers in the dorsal spinal roots," The Japanese Journal of Physiology, vol. 55, no. 3, pp. 149-155, 2005.

[67] C. Y. Chiang, C.T. Chang, H. L. Chu et al., "Peripheral afferent pathway for acupuncture analgesia," Scientia Sinica, vol. 16, pp. 210-217, 1973.

[68] H. Ohsawa, K. Okada, K. Nishijo, and Y. Sato, "Neural mechanism of depressor responses of arterial pressure elicited by acupuncture-like stimulation to a hindlimb in anesthetized rats," Journal of the Autonomic Nervous System, vol. 51, no. 1, pp. 27-35, 1995.

[69] S. Uchida, M. Shimura, H. Ohsawa, and A. Suzuki, "Neural mechanism of bradycardiac responses elicited by acupuncture-like stimulation to a hind limb in anesthetized rats," The Journal of Physiological Sciences, vol. 57, no. 6, pp. 377-382, 2007.

[70] A. Benham, G. Phillips, and M. I. Johnson, "An experimental study on the self-report of acupuncture needle sensation during deep needling with bi-directional rotation," Acupuncture in Medicine, vol. 28, no. 1, pp. 16-20, 2010.

[71] B. Flaws and J. Lake, "Spirit-quieting, mind-stabilizing acupuncture points," in Chinese Medical Psychiatry (A Textbook and Clinical Manual), chapter 5, pp. 63-65, Blue Poppy Press, New York, NY, USA, 2005.
[72] A. U. Asghar, G. Green, M. F. Lythgoe, G. Lewith, and H. MacPherson, "Acupuncture needling sensation: the neural correlates of deqi using fMRI," Brain Research, vol. 1315, pp. 111-118, 2010.

[73] K. K. Hui, O. Marina, J. Liu, B. R. Rosen, and K. K. Kwong, "Acupuncture, the limbic system, and the anticorrelated networks of the brain," Autonomic Neuroscience, vol. 157, no. 12, pp. 81-90, 2010.

[74] C. S. Yin, H. J. Park, S. Y. Kim et al., "Electroencephalogram changes according to the subjective acupuncture sensation," Neurological Research, vol. 32, supplement 1, pp. S31-S36, 2010.

[75] P. White, P. Prescott, and G. Lewith, "Does needling sensation (de qi) affect treatment outcome in pain? Analysis of data from a larger single-blind, randomised controlled trial," Acupuncture in Medicine, vol. 28, no. 3, pp. 120-125, 2010.

[76] A. Benham and M. I. Johnson, "Could acupuncture needle sensation be a predictor of analgesic response?" Acupuncture in Medicine, vol. 27, no. 2, pp. 65-67, 2009.

[77] T. C. Kuo, C. W. Lin, and F. M. Ho, "The soreness and numbness effect of acupuncture on skin blood flow," The American Journal of Chinese Medicine, vol. 32, no. 1, pp. 117129, 2004.

[78] M. Sandberg, T. Lundeberg, L. G. Lindberg, and B. Gerdle, "Effects of acupuncture on skin and muscle blood flow in healthy subjects," European Journal of Applied Physiology, vol. 90, no. 1-2, pp. 114-119, 2003.

[79] J. Kong, D. T. Fufa, A. J. Gerber et al., "Psychophysical outcomes from a randomized pilot study of manual, electro, and sham acupuncture treatment on experimentally induced thermal pain," The Journal of Pain, vol. 6, no. 1, pp. 55-64, 2005.

[80] K. M. Wang, S. M. Yao, Y. L. Xian, and Z. L. Hou, "A study on the receptive field of acupoints and the relationship between characteristics of needling sensation and groups of afferent fibres," Scientia Sinica B, vol. 28, no. 9, pp. 963-971, 1985.

[81] K. Wang and J. Liu, "Needling sensation receptor of an acupoint supplied by the median nerve-studies of their electro-physiological characteristics," The American Journal of Chinese Medicine, vol. 17, no. 3-4, pp. 145-156, 1989.

[82] H. Zonglian, "A study on the histologic structure of acupuncture points and types of fibers conveying needling sensation," Chinese Medical Journal, vol. 92, no. 4, pp. 223-232, 1979.

[83] D. Bowsher, "Mechanisms of acupuncture," in Medical Acupuncture: A Western Scientific Approach, J. Filshie and A. White, Eds., pp. 69-82, Churchill Livingstone, Edinburgh, UK, 1998.

[84] A. Skokljev and E. Koruga, "The role of trigeminal nerve in acupuncture," Acupuncture and Electro-Therapeutics Research, vol. 13, no. 2-3, pp. 67-78, 1988.

[85] A. Li, Y. Wang, J. Xin et al., "Electroacupuncture suppresses hyperalgesia and spinal Fos expression by activating the descending inhibitory system," Brain Research, vol. 1186, no. 1, pp. 171-179, 2007.

[86] G. van Wijk and D. S. Veldhuijzen, "Perspective on diffuse noxious inhibitory controls as a model of endogenous pain modulation in clinical pain syndromes," The Journal of Pain, vol. 11, no. 5, pp. 408-419, 2010.

[87] K. J. Berkley and C. H. Hubscher, "Are there separate central nervous system pathways for touch and pain?" Nature Medicine, vol. 1, no. 8, pp. 766-773, 1995.

[88] S. X. Ma and X. Y. Li, "Increased neuronal nitric oxide synthase expression in the gracile nucleus of brainstem following electroacupuncture given between cutaneous hindlimb 
acupuncture points BL 64 \& BL 65 in rats," Acupuncture and Electro-Therapeutics Research, vol. 27, no. 3-4, pp. 157-169, 2002.

[89] F. Zhang, Y. Feng, R. Zhou, Y. Q. Zhang, and B. Y. Chen, "Observation on the central afferent pathway of "Guanyuan" (CV 4) under normal and pathological states and the influence of electroacupuncture," Zhen Ci Yan Jiu, vol. 33, no. 3, pp. 147-153, 2008.

[90] S. Chen and S. X. Ma, "Nitric oxide in the gracile nucleus mediates depressor response to acupuncture (ST36)," Journal of Neurophysiology, vol. 90, no. 2, pp. 780-785, 2003.

[91] S. X. Ma, "Neurobiology of acupuncture: toward CAM," Evidence-based Complementary and Alternative Medicine, vol. 1, no. 1, pp. 41-47, 2004.

[92] E. Urasaki, S. Wada, H. Yasukouchi, and A. Yokota, "Effect of transcutaneous electrical nerve stimulation (TENS) on central nervous system amplification of somatosensory input," Journal of Neurology, vol. 245, no. 3, pp. 143-148, 1998.

[93] M. A. Arbab, T. Delgado, L. Wiklund, and N. A. Svendgaard, "Brain stem terminations of the trigeminal and upper spinal ganglia innervation of the cerebrovascular system: WGAHRP transganglionic study," Journal of Cerebral Blood Flow and Metabolism, vol. 8, no. 1, pp. 54-63, 1988.

[94] K. Kubota, N. Narita, K. Ohkubo et al., "Central projection of proprioceptive afferents arising from maxillo-facial regions in some animals studied by HRP-labeling technique," Anatomischer Anzeiger, vol. 165, no. 2-3, pp. 229-251, 1988.

[95] S. L. Foote, F. E. Bloom, and G. Aston Jones, "Nucleus locus ceruleus: new evidence of anatomical and physiological specificity," Physiological Reviews, vol. 63, no. 3, pp. 844-914, 1983.

[96] K. L. Simpson, D. W. Altman, L. Wang, M. L. Kirifides, R. C. S. Lin, and B. D. Waterhouse, "Lateralization and functional organization of the locus coeruleus projection to the trigeminal somatosensory pathway in rat," The Journal of Comparative Neurology, vol. 385, no. 1, pp. 135-147, 1997.

[97] K. L. Simpson, B. D. Waterhouse, and R. C. Lin, "Origin, distribution, and morphology of galaninergic fibers in the rodent trigeminal system," Journal of Comparative Neurology, vol. 411, no. 3, pp. 524-534, 1999.

[98] T. Takahashi, M. Shirasu, M. Shirasu et al., "The locus coeruleus projects to the mesencephalic trigeminal nucleus in rats," Neuroscience Research, vol. 68, no. 2, pp. 103-106, 2010.

[99] J. M. Monti, "The structure of the dorsal raphe nucleus and its relevance to the regulation of sleep and wakefulness," Sleep Medicine Reviews, vol. 14, no. 5, pp. 307-317, 2010.

[100] N. Singewald and A. Philippu, "Release of neurotransmitters in the locus coeruleus," Progress in Neurobiology, vol. 56, no. 2, pp. 237-267, 1998.

[101] Z. Fang, "Expression of somatostatin mRNA and coexistence of SOM mRNA and 5-HT in nucleus raphe dorsalis following noxious stimulation and electroacupuncture analgesia," Zhen Ci Yan Jiu, vol. 21, no. 3, pp. 22-26, 1996.

[102] Y. B. Kwon, M. S. Kang, S. S. Son et al., "Different frequencies of electroacupuncture modified the cellular activity of serotonergic neurons in brainstem," The American Journal of Chinese Medicine, vol. 28, no. 3-4, pp. 435-441, 2000.

[103] Y. Kwon, M. Kang, C. Ahn, H. J. Han, B. C. Ahn, and J. H. Lee, "Effect of high or low frequency electroacupuncture on the cellular activity of catecholaminergic neurons in the brain stem," Acupuncture and Electro-Therapeutics Research, vol. 25, no. 1, pp. 27-36, 2000.
[104] H. J. Lee, B. Lee, S. H. Choi et al., "Electroacupuncture reduces stress-induced expression of c-Fos in the brain of the rat," The American Journal of Chinese Medicine, vol. 32, no. 5, pp. 795-806, 2004.

[105] H. J. Park, H. Y. Kim, D. H. Hahm, H. Lee, K. S. Kim, and I. Shim, "Electroacupuncture to ST36 ameliorates behavioral and biochemical responses to restraint stress in rats," Neurological Research, vol. 32, supplement 1, pp. S111-S115, 2010.

[106] W. Tang, "Clinical observation on scalp acupuncture treatment in 50 cases of headache," Journal of Traditional Chinese Medicine, vol. 22, no. 3, pp. 190-192, 2002.

[107] Z. J. Zhang, X. Y. Wang, Q. R. Tan, G. X. Jin, and S. M. Yao, "Electroacupuncture for refractory obsessive-compulsive disorder: a pilot waitlist-controlled trial," Journal of Nervous and Mental Disease, vol. 197, no. 8, pp. 619-622, 2009.

[108] Y. Huang, W. Gong, J. Zou et al., "An SCL-90 analysis of scalp electroacupuncture treatment of major depressive episode," Shanghai Zhen Jiu Za Zhi, vol. 23, pp. 5-7, 2004.

[109] Y. Huang, J. Chen, and J. Zou, "Effect of scalp electroacupuncture on post-stroke depression," Zhong Guo Kang Fu, vol. 9, no. 40, pp. 172-173, 2005.

[110] Y. Huang, X. S. Lai, and A. W. Tang, "Comparative study of the specificities of needling acupoints DU20, DU26 and HT7 in intervening vascular dementia in different areas in the brain on the basis of scale assessment and cerebral functional imaging," Chinese Journal of Integrative Medicine, vol. 13, no. 2, pp. 103-108, 2007.

[111] Z. J. Zhang, R. Ng, S. C. Man et al., "Dense cranial electroacupuncture stimulation for major depressive disorder a single-blind, randomized, controlled study," Plos One, vol. 7, no. 1, Article ID e29651, 2012.

[112] R. P. Dhond, N. Kettner, and V. Napadow, "Neuroimaging acupuncture effects in the human brain," Journal of Alternative and Complementary Medicine, vol. 13, no. 6, pp. 603-616, 2007.

[113] Z. H. Cho, S. C. Chung, J. P. Jones et al., "New findings of the correlation between acupoints and corresponding brain cortices using functional MRI," Proceedings of the National Academy of Sciences of the United States of America, vol. 95, no. 5, pp. 2670-2673, 1998.

[114] G. Li, R. T. Cheung, Q. Y. Ma, and E. S. Yang, "Visual cortical activations on fMRI upon stimulation of the vision-implicated acupoints," NeuroReport, vol. 14, no. 5, pp. 669-673, 2003.

[115] M. T. Wu, J. M. Sheen, K. H. Chuang et al., "Neuronal specificity of acupuncture response: a fMRI study with electroacupuncture," NeuroImage, vol. 16, no. 4, pp. 10281037, 2002.

[116] F. Beissner and C. Henke, "Methodological problems in fMRI studies on acupuncture: a critical review with special emphasis on visual and auditory cortex activations," Evidence-Based Complementary and Alternative Medicine, vol. 2011, Article ID 607637, 7 pages, 2011.

[117] Y. Chae, H. J. Park, D. H. Hahm et al., "fMRI review on brain responses to acupuncture: the limitations and possibilities in traditional Korean acupuncture," Neurological Research, vol. 29, supplement 1, pp. S42-S48, 2007.

[118] Y. Chae, H. Lee, H. Kim, H. Sohn, J. H. Park, and H. J. Park, "The neural substrates of verum acupuncture compared to non-penetrating placebo needle: an fMRI study," Neuroscience Letters, vol. 450, no. 2, pp. 80-84, 2009.

[119] R. P. Dhond, N. Kettner, and V. Napadow, "Do the neural correlates of acupuncture and placebo effects differ?" Pain, vol. 128 , no. $1-2$, pp. 8-12, 2007. 
[120] J. L. Fang, T. Krings, J. Weidemann, I. G. Meister, and A. Thron, "Functional MRI in healthy subjects during acupuncture: different effects of needle rotation in real and false acupoints," Neuroradiology, vol. 46, no. 5, pp. 359-362, 2004.

[121] B. J. Na, G. H. Jahng, S. U. Park et al., "An fMRI study of neuronal specificity of an acupoint: electroacupuncture stimulation of Yanglingquan (GB34) and its sham point," Neuroscience Letters, vol. 464, no. 1, pp. 1-5, 2009.

[122] T. B. Parrish, A. Schaeffer, M. Catanese et al., "Functional magnetic resonance imaging of real and sham acupuncture. Noninvasively measuring cortical activation from acupuncture," IEEE Engineering in Medicine and Biology Magazine, vol. 24, no. 2, pp. 35-40, 2005.

[123] Y. Wu, Z. Jin, K. Li et al., "Functional magnetic resonance imaging activation of the brain in children: real acupoint versus sham acupoint," Journal of Child Neurology, vol. 25, no. 7, pp. 849-855, 2010.

[124] B. Yan, K. Li, J. Xu et al., "Acupoint-specific fMRI patterns in human brain," Neuroscience Letters, vol. 383, no. 3, pp. 236240, 2005.

[125] S. Y. Cho, G. H. Jahng, S. U. Park, W. S. Jung, S. K. Moon, and J. M. Park, "FMRI study of effect on brain activity according to stimulation method at LI11, ST36: painful pressure and acupuncture stimulation of same acupoints," Journal of Alternative and Complementary Medicine, vol. 16, no. 4, pp. 489-495, 2010.

[126] J. H. Zhang, X. D. Cao, J. Li, W. J. Tang, H. Q. Liu, and X. Y. Feng, "Neuronal specificity of needling acupoints at same meridian: a control functional magnetic resonance imaging study with electroacupuncture," Acupuncture and ElectroTherapeutics Research, vol. 32, no. 3-4, pp. 179-193, 2007.

[127] K. Li, B. Shan, J. Xu et al., "Changes in fMRI in the human brain related to different durations of manual acupuncture needling," Journal of Alternative and Complementary Medicine, vol. 12, no. 7, pp. 615-623, 2006.

[128] K. K. Hui, E. E. Nixon, M. G. Vangel et al., "Characterization of the "deqi" response in acupuncture," BMC Complementary and Alternative Medicine, vol. 7, article 33, 2007.

[129] Z. H. Cho, S. C. Hwang, E. K. Wong et al., "Neural substrates, experimental evidences and functional hypothesis of acupuncture mechanisms," Acta Neurologica Scandinavica, vol. 113, no. 6, pp. 370-377, 2006.

[130] J. S. Han, "Acupuncture: neuropeptide release produced by electrical stimulation of different frequencies," Trends in Neurosciences, vol. 26, no. 1, pp. 17-22, 2003.

[131] Y. B. Kwon, M. S. Kang, S. S. Son et al., "Different frequencies of electroacupuncture modified the cellular activity of serotonergic neurons in brainstem," The American Journal of Chinese Medicine, vol. 28, no. 3-4, pp. 435-441, 2000.

[132] Q. P. Ma, Y. Zhou, Y. X. Yu, and J. S. Han, "Electroacupuncture accelerated the expression of c-fos protooncogene in serotonergic neurons of nucleus raphe dorsalis," International Journal of Neuroscience, vol. 67, no. 1-4, pp. 111-117, 1992.

[133] M. F. Levin and C. W. Hui-Chan, "Conventional and acupuncture-like transcutaneous electrical nerve stimulation excite similar afferent fibers," Archives of Physical Medicine and Rehabilitation, vol. 74, no. 1, pp. 54-60, 1993.

[134] G. G. Xing, F. Y. Liu, X. X. Qu, J. S. Han, and Y. Wan, "Longterm synaptic plasticity in the spinal dorsal horn and its modulation by electroacupuncture in rats with neuropathic pain," Experimental Neurology, vol. 208, no. 2, pp. 323-332, 2007.
[135] Z. Jin, W. T. Zhang, F. Luo et al., "Frequency-specific responses of human brain to peripheral transcutaneous electric nerve stimulation: a functional magnetic resonance imaging study," Sheng Li Xue Bao, vol. 53, no. 4, pp. 275-280, 2001.

[136] W. T. Zhang, Z. Jin, G. H. Cui et al., "Relations between brain network activation and analgesic effect induced by low vs. high frequency electrical acupoint stimulation in different subjects: a functional magnetic resonance imaging study," Brain Research, vol. 982, no. 2, pp. 168-178, 2003.

[137] H. F. Guo, J. Tian, X. Wang, Y. Fang, Y. Hou, and J. Han, "Brain substrates activated by electroacupuncture of different frequencies (I): comparative study on the expression of oncogene c-fos and genes coding for three opioid peptides," Molecular Brain Research, vol. 43, no. 1-2, pp. 157-166, 1996.

[138] V. Napadow, N. Kettner, J. Liu et al., "Hypothalamus and amygdala response to acupuncture stimuli in carpal tunnel syndrome," Pain, vol. 130, no. 3, pp. 254-266, 2007.

[139] A. B. Newberg, P. J. LaRiccia, B. Y. Lee, J. T. Farrar, L. Lee, and A. Alavi, "Cerebral blood flow effects of pain and acupuncture: a preliminary single-photon emission computed tomography imaging study," Journal of Neuroimaging, vol. 15, no. 1, pp. 43-49, 2005.

[140] J. H. Zhang, J. Li, X. D. Cao, and X. Y. Feng, "Can electroacupuncture affect the sympathetic activity, estimated by skin temperature measurement? A functional MRI study on the effect of needling at GB 34 and GB 39 on patients with pain in the lower extremity," Acupuncture \& ElectroTherapeutics Research, vol. 34, no. 3-4, pp. 151-164, 2009.

[141] Y. Wu, Z. Jin, K. Li et al., "Effect of acupuncture on the brain in children with spastic cerebral palsy using functional neuroimaging (fMRI)," Journal of Child Neurology, vol. 23, no. 11, pp. 1267-1274, 2008.

[142] A. C. Chau, R. T. Fai Cheung, X. Jiang, P. K. M. Au-Yeung, and L. S. W. Li, "An fMRI study showing the effect of acupuncture in chronic stage stroke patients with aphasia," Journal of Acupuncture and Meridian Studies, vol. 3, no. 1, pp. 53-57, 2010.

[143] J. D. Lee, J. S. Chon, H. K. Jeong et al., "The cerebrovascular response to traditional acupuncture after stroke," Neuroradiology, vol. 45, no. 11, pp. 780-784, 2003.

[144] G. Li, C. R. Jack, and E. S. Yang, "An fMRI study of somatosensory-implicated acupuncture points in stable somatosensory stroke patients," Journal of Magnetic Resonance Imaging, vol. 24, no. 5, pp. 1018-1024, 2006.

[145] J. D. Schaechter, B. D. Connell, W. B. Stason et al., "Correlated change in upper limb function and motor cortex activation after verum and sham acupuncture in patients with chronic stroke," Journal of Alternative and Complementary Medicine, vol. 13, no. 5, pp. 527-532, 2007.

[146] Y. Chae, H. Lee, H. Kim et al., "Parsing brain activity associated with acupuncture treatment in Parkinson's diseases," Movement Disorders, vol. 24, no. 12, pp. 1794-1802, 2009.

[147] Y. Zhou and J. Jia, "Effect of acupuncture given at the HT 7, ST 36, ST 40 and KI 3 acupoints on various parts of the brains of Alzheimer's disease patients," Acupuncture and ElectroTherapeutics Research, vol. 33, no. 1-2, pp. 9-17, 2008.

[148] D. M. Duan, Y. Tu, L. P. Chen, and Z. J. Wu, "Study on electroacupuncture treatment of depression by magnetic resonance imaging," Zhongguo Zhen Jiu, vol. 29, no. 2, pp. 139144, 2009.

[149] Y. Huang, D. J. Li, A. W. Tang et al., "Effect of scalp acupuncture on glucose metabolism in brain of patients with 
depression," Zhongguo Zhong Xi Yi Jie He Za Zhi, vol. 25, no. 2, pp. 119-122, 2005.

[150] S. Liu, W. Zhou, X. Ruan et al., "Activation of the hypothalamus characterizes the response to acupuncture stimulation in heroin addicts," Neuroscience Letters, vol. 421, no. 3, pp. 203-208, 2007.

[151] V. F. Markelova, S. M. Zol'nikov, R. A. Belitskaia, T. P. Ponomarenko, and O. V. Shumova, "Changes in biogenic amine levels in the blood and urine during anesthesia using electroacupuncture," Anesteziologiia i Reanimatologiia, no. 6, pp. 36-39, 1985.

[152] Y. Song, D. Zhou, J. Fan, H. Luo, and U. Halbreich, "Effects of electroacupuncture and fluoxetine on the density of GTP-binding-proteins in platelet membrane in patients with major depressive disorder," Journal of Affective Disorders, vol. 98, no. 3, pp. 253-257, 2007.

[153] J. G. Dos Santos, F. Kawano, M. M. Nishida, Y. Yamamura, L. E. Mello, and A. Tabosa, "Antidepressive-like effects of electroacupuncture in rats," Physiology \& Behavior, vol. 93, no. 1-2, pp. 155-159, 2008.

[154] S. F. Xu, L. X. Zhuang, C. Z. Tang, and J. J. Yang, "Effects of acupuncture and embedding thread on central monoamine neurotransmitters in the depression model rat," Zhongguo Zhen Jiu, vol. 27, no. 6, pp. 435-437, 2007.

[155] J. Yu, X. Y. Li, X. D. Cao, and G. C. Wu, "Sucrose preference is restored by electro-acupuncture combined with chlorimipramine in the depression-model rats," Acupuncture and Electro-Therapeutics Research, vol. 31, no. 3-4, pp. 223-232, 2006.

[156] J. Yu, Q. Liu, Y. Q. Wang et al., "Electroacupuncture combined with clomipramine enhances antidepressant effect in rodents," Neuroscience Letters, vol. 421, no. 1, pp. 5-9, 2007.

[157] C. M. Guimarães, M. C. Pinge, Y. Yamamura, and L. E. Mello, "Effects of acupuncture on behavioral, cardiovascular and hormonal responses in restraint-stressed Wistar rats," Brazilian Journal of Medical and Biological Research, vol. 30, no. 12, pp. 1445-1450, 1997.

[158] K. Imai, H. Ariga, and T. Takahashi, "Electroacupuncture improves imbalance of autonomic function under restraint stress in conscious rats," The American Journal of Chinese Medicine, vol. 37, no. 1, pp. 45-55, 2009.

[159] M. Iwa, Y. Nakade, T. N. Pappas, and T. Takahashi, "Electroacupuncture improves restraint stress-induced delay of gastric emptying via central glutaminergic pathways in conscious rats," Neuroscience Letters, vol. 399, no. 1-2, pp. 610, 2006.

[160] B. Lee, I. Shim, H. J. Lee, Y. Yang, and D. H. Hahm, "Effects of acupuncture on chronic corticosterone-induced depressionlike behavior and expression of neuropeptide $\mathrm{Y}$ in the rats," Neuroscience Letters, vol. 453, no. 3, pp. 151-156, 2009.

[161] M. A. Medeiros, N. S. Canteras, D. Suchecki, and L. E. A. M. Mello, "c-Fos expression induced by electroacupuncture at the Zusanli point in rats submitted to repeated immobilization," Brazilian Journal of Medical and Biological Research, vol. 36, no. 12, pp. 1673-1684, 2003.

[162] C. H. Yang, B. B. Lee, H. S. Jung, I. Shim, P. U. Roh, and G. T. Golden, "Effect of electroacupuncture on response to immobilization stress," Pharmacology Biochemistry and Behavior, vol. 72, no. 4, pp. 847-855, 2002.

[163] S. J. Yun, H. J. Park, M. J. Yeom, D. H. Hahm, H. J. Lee, and E. H. Lee, "Effect of electroacupuncture on the stress-induced changes in brain-derived neurotrophic factor expression in rat hippocampus," Neuroscience Letters, vol. 318, no. 2, pp. 85-88, 2002.

[164] H. J. Kim, H. J. Park, M. S. Hong et al., "Effect by acupuncture on hypothalamic expression of maternally separated rats: proteomic approach," Neurological Research, vol. 32, supplement 1, pp. S69-S73, 2010.

[165] S. Lim, Y. H. Ryu, S. T. Kim, M. S. Hong, and H. J. Park, "Acupuncture increases neuropeptide Y expression in hippocampus of maternally-separated rats," Neuroscience Letters, vol. 343, no. 1, pp. 49-52, 2003.

[166] H. J. Park, Y. Chae, J. Jang, I. Shim, H. Lee, and S. Lim, "The effect of acupuncture on anxiety and neuropeptide $\mathrm{Y}$ expression in the basolateral amygdala of maternally separated rats," Neuroscience Letters, vol. 377, no. 3, pp. 179184, 2005.

[167] H. Kim, H. J. Park, S. M. Han et al., "The effects of acupuncture stimulation at PC6 (Neiguan) on chronic mild stressinduced biochemical and behavioral responses," Neuroscience Letters, vol. 460, no. 1, pp. 56-60, 2009.

[168] Q. Liu, J. Yu, W. L. Mi et al., "Electroacupuncture attenuates the decrease of hippocampal progenitor cell proliferation in the adult rats exposed to chronic unpredictable stress," Life Sciences, vol. 81, no. 21-22, pp. 1489-1495, 2007.

[169] J. Wang, H. Zhao, Q. L. Mao-Ying, X. D. Cao, Y. Q. Wang, and G. C. Wu, "Electroacupuncture downregulates TLR2/4 and pro-inflammatory cytokine expression after surgical trauma stress without adrenal glands involvement," Brain Research Bulletin, vol. 80, no. 1-2, pp. 89-94, 2009.

[170] J. P. Sun, H. T. Pei, X. L. Jin, L. Yin, Q. H. Tian, and S. J. Tian, "Effects of acupuncturing Tsusanli (ST36) on expression of nitric oxide synthase in hypothalamus and adrenal gland in rats with cold stress ulcer," World Journal of Gastroenterology, vol. 11, no. 32, pp. 4962-4966, 2005.

[171] S. H. Han, S. H. Yoon, Y. W. Cho, C. J. Kim, and B. I. Min, "Inhibitory effects of electroacupuncture on stress responses evoked by tooth-pulp stimulation in rats," Physiology and Behavior, vol. 66, no. 2, pp. 217-222, 1999.

[172] P. J. Rong, B. Zhu, Q. F. Huang, X. Y. Gao, H. Ben, and Y. $\mathrm{H}$. Li, "Acupuncture inhibition on neuronal activity of spinal dorsal horn induced by noxious colorectal distension in rat," World Journal of Gastroenterology, vol. 11, no. 7, pp. 10111017, 2005.

[173] J. Yin and J. D. Chen, "Gastrointestinal motility disorders and acupuncture," Autonomic Neurosciencep, vol. 157, no. 1-2, pp. 31-37, 2010.

[174] T. Takahashi, "Acupuncture for functional gastrointestinal disorders," Journal of Gastroenterology, vol. 41, no. 5, pp. 408417, 2006.

[175] S. Lee, M. S. Lee, J. Y. Choi, S. W. Lee, S. Y. Jeong, and E. Ernst, "Acupuncture and heart rate variability: a systematic review," Autonomic Neurosciencep, vol. 155, no. 1-2, pp. 5-13, 2010.

[176] P. Li and J. C. Longhurst, "Neural mechanism of electroacupuncture's hypotensive effects," Autonomic Neuroscience, vol. 157, no. 1-2, pp. 24-30, 2010.

[177] L. H. Thomas, S. Cross, J. Barrett et al., "Treatment of urinary incontinence after stroke in adults," Cochrane Database of Systematic Reviews, no. 1, Article ID CD004462, 2008.

[178] J. Martin, A. N. Donaldson, R. Villarroel, M. K. B. Parmar, E. Ernst, and I. J. Higginson, "Efficacy of acupuncture in asthma: systematic review and meta-analysis of published data from 11 randomised controlled trials," The European Respiratory Journal, vol. 20, no. 4, pp. 846-852, 2002. 
[179] F. Kagitani, S. Uchida, and H. Hotta, "Afferent nerve fibers and acupuncture," Autonomic Neuroscience, vol. 157, no. 1-2, pp. 2-8, 2010.

[180] E. Noguchi, "Acupuncture regulates gut motility and secretion via nerve reflexes," Autonomic Neuroscience, vol. 156, no. $1-2$, pp. 15-18, 2010.

[181] V. A. Pavlov and K. J. Tracey, "Neural regulators of innate immune responses and inflammation," Cellular and Molecular Life Sciences, vol. 61, no. 18, pp. 2322-2331, 2004.

[182] K. M. Buller, "Neuroimmune stress responses: reciprocal connections between the hypothalamus and the brainstem," Stress, vol. 6, no. 1, pp. 11-17, 2003.

[183] I. Hickie and A. Lloyd, "Are cytokines associated with neuropsychiatric syndromes in humans?" International Journal of Immunopharmacology, vol. 17, no. 8, pp. 677-683, 1995.

[184] D. Kerr, C. Krishnan, M. L. Pucak, and J. Carmen, "The immune system and neuropsychiatric diseases," International Review of Psychiatry, vol. 17, no. 6, pp. 443-449, 2005.

[185] A. H. Miller, V. Maletic, and C. L. Raison, "Inflammation and its discontents: the role of cytokines in the pathophysiology of major depression," Biological Psychiatry, vol. 65, no. 9, pp. 732-741, 2009.

[186] J. K. Kiecolt-Glaser, L. McGuire, T. F. Robles, and R. Glaser, "Psychoneuroimmunology and psychosomatic medicine: back to the future," Psychosomatic Medicine, vol. 64, no. 1, pp. 15-28, 2002.

[187] M. M. Backonja, C. L. Coe, D. A. Muller, and K. Schell, "Altered cytokine levels in the blood and cerebrospinal fluid of chronic pain patients," Journal of Neuroimmunology, vol. 195, no. 1-2, pp. 157-163, 2008.

[188] N. D. Brunetti, I. Munno, P. L. Pellegrino et al., "Inflammatory cytokines imbalance in the very early phase of acute coronary syndrome: correlations with angiographic findings and in-hospital events," Inflammation, vol. 34, no. 1, pp. 5866, 2011.

[189] N. Uçeyler, M. Schäfers, and C. Sommer, "Mode of action of cytokines on nociceptive neurons," Experimental Brain Research, vol. 196, no. 1, pp. 67-78, 2009.

[190] N. Uçeyler and C. Sommer, "Status of immune mediators in painful neuropathies," Current Pain and Headache Reports, vol. 12, no. 3, pp. 159-164, 2008.

[191] D. Marazziti, F. Ambrogi, R. Vanacorea et al., "Immune cell imbalance in major depressive and panic disorders," Neuropsychobiology, vol. 26, no. 1-2, pp. 23-26, 1992.

[192] C. Song, U. Halbreich, C. Han, B. E. Leonard, and H. Luo, "Imbalance between Pro- and Anti-inflammatory cytokines, and between Th1 and Th2 cytokines in depressed patients: the effect of electroacupuncture or fluoxetine treatment," Pharmacopsychiatry, vol. 42, no. 5, pp. 182-188, 2009.

[193] B. E. Leonard, "The HPA and immune axes in stress: the involvement of the serotonergic system," European Psychiatry, vol. 20, supplement 3, pp. S302-S306, 2005.

[194] L. Dyugovskaya, P. Lavie, and L. Lavie, "Lymphocyte activation as a possible measure of atherosclerotic risk in patients with sleep apnea," Annals of the New York Academy of Sciences, vol. 1051, pp. 340-350, 2005.

[195] S. ThyagaRajan and D. L. Felten, "Modulation of neuroendocrine-immune signaling by L-deprenyl and L-desmethyldeprenyl in aging and mammary cancer," Mechanisms of Ageing and Development, vol. 123, no. 8, pp. 1065-1079, 2002.

[196] Y. M. Liu, X. J. Liu, S. S. Bai et al., "The effect of electroacupuncture on $\mathrm{T}$ cell responses in rats with experimental autoimmune encephalitis," Journal of Neuroimmunology, vol. 220, no. $1-2$, pp. 25-33, 2010.
[197] K. Wang, H. Wu, G. Wang, M. Li, Z. Zhang, and G. Gu, “The effects of electroacupuncture on Th1/Th2 cytokine mRNA expression and mitogen-activated protein kinase signaling pathways in the splenic T cells of traumatized rats," Anesthesia and Analgesia, vol. 109, no. 5, pp. 1666-1673, 2009.

[198] W. T. Zhang, Z. Jin, F. Luo, L. Zhang, Y. W. Zeng, and J. S. Han, "Evidence from brain imaging with fMRI supporting functional specificity of acupoints in humans," Neuroscience Letters, vol. 354, no. 1, pp. 50-53, 2004.

[199] K. Streitberger and J. Kleinhenz, "Introducing a placebo needle into acupuncture research," The Lancet, vol. 352, no. 9125, pp. 364-365, 1998.

[200] K. Linde, K. Niemann, A. Schneider, and K. Meissner, "How large are the nonspecific effects of acupuncture? A metaanalysis of randomized controlled trials," BMC Medicine, vol. 8, article 75, 2010.

[201] Z. J. Zhang, H. Y. Chen, K. C. Yip, R. Ng, and V. T. Wong, "The effectiveness and safety of acupuncture therapy in depressive disorders: systematic review and meta-analysis," Journal of Affective Disorders, vol. 124, no. 1-2, pp. 9-21, 2010.

[202] A. White, M. Cummings, P. Barlas et al., "Defining an adequate dose of acupuncture using a neurophysiological approach-a narrative review of the literature," Acupuncture in Medicine, vol. 26, no. 2, pp. 111-120, 2008.

[203] S. M. Carlton and R. E. Coggeshall, "Immunohistochemical localization of 5-HT(2A) receptors in peripheral sensory axons in rat glabrous skin," Brain Research, vol. 763, no. 2, pp. 271-275, 1997.

[204] H. Klapproth, T. Reinheimer, J. Metzen et al., "Non-neuronal acetylcholine, a signalling molecule synthezised by surface cells of rat and man," Naunyn-Schmiedeberg's Archives of Pharmacology, vol. 355, no. 4, pp. 515-523, 1997.

[205] K. Nordlind, O. Johansson, S. Lidén, and T. Hokfelt, "Glutamate- and aspartate-like immunoreactivities in human normal and inflamed skin," Virchows Archiv B, vol. 64, no. 2, pp. 75-82, 1993.

[206] R. Nigam, H. El-Nour, B. Amatya, and K. Nordlind, "GABA and GABAA receptor expression on immune cells in psoriasis: a pathophysiological role," Archives of Dermatological Research, vol. 302, no. 7, pp. 507-515, 2010.

[207] J. Woodcock, J. Witter, and R. A. Dionne, "Stimulating the development of mechanism-based, individualized pain therapies," Nature Reviews: Drug Discovery, vol. 6, no. 9, pp. 703-710, 2007.

[208] S. Pain, C. Dezutter, C. Reymermier, B. Vogelgesang, E. Delay, and V. André, "Age-related changes in pro-opiomelanocortin (POMC) and related receptors in human epidermis," International Journal of Cosmetic Science, vol. 32, no. 4, pp. 266275, 2010.

[209] L. Bracci-Laudiero, L. Aloe, P. Buanne et al., "NGF modulates CGRP synthesis in human B-lymphocytes: a possible antiinflammatory action of NGF?" Journal of Neuroimmunology, vol. 123 , no. 1-2, pp. 58-65, 2002.

[210] A. B. Kay, "Calcitonin gene-related peptide- and vascular endothelial growth factor-positive inflammatory cells in latephase allergic skin reactions in atopic subjects," The Journal of Allergy and Clinical Immunology, vol. 127, no. 1, pp. 232-237, 2011.

[211] S. M. Carlton, J. Du, E. Davidson, S. Zhou, and R. E. Coggeshall, "Somatostatin receptors on peripheral primary afferent terminals: inhibition of sensitized nociceptors," Pain, vol. 90, no. 3, pp. 233-244, 2001.

[212] S. M. Carlton, J. Du, S. Zhou, and R. E. Coggeshall, “Tonic control of peripheral cutaneous nociceptors by somatostatin 
receptors," The Journal of Neuroscience, vol. 21, no. 11, pp. 4042-4049, 2001.

[213] M. Vockel, U. Breitenbach, H. J. Kreienkamp et al., "Somatostatin regulates tight junction function and composition in human keratinocytes," Experimental Dermatology, vol. 19, no. 10 , pp. $888-894,2010$.

[214] N. T. Jou and S. X. Ma, "Responses of nitric oxide-cGMP release in acupuncture point to electroacupuncture in human skin in vivo using dermal microdialysis," Microcirculation, vol. 16, no. 5, pp. 434-443, 2009.

[215] M. Tsuchiya, E. F. Sato, M. Inoue, and A. Asada, "Acupuncture enhances generation of nitric oxide and increases local circulation," Anesthesia and Analgesia, vol. 104, no. 2, pp. 301-307, 2007.

[216] G. Burnstock, "Acupuncture: a novel hypothesis for the involvement of purinergic signalling," Medical Hypotheses, vol. 73, no. 4, pp. 470-472, 2009.

[217] A. Dray and M. Perkins, "Bradykinin and inflammatory pain," Trends in Neurosciences, vol. 16, no. 3, pp. 99-104, 1993.

[218] A. Dray, "Inflammatory mediators of pain," British Journal of Anaesthesia, vol. 75, no. 2, pp. 125-131, 1995.

[219] B. R. Conklin, R. M. Burch, L. R. Steranka, and J. Axelrod, "Distinct bradykinin receptors mediate stimulation of prostaglandin synthesis by endothelial cells and fibroblasts," The Journal of Pharmacology and Experimental Therapeutics, vol. 244, no. 2, pp. 646-649, 1988.

[220] M. D. Southall, T. Li, L. S. Gharibova, Y. Pei, G. D. Nicol, and J. B. Travers, "Activation of epidermal vanilloid receptor-1 induces release of proinflammatory mediators in human keratinocytes," The Journal of Pharmacology and Experimental Therapeutics, vol. 304, no. 1, pp. 217-222, 2003.

[221] X. M. Wang, M. Hamza, T. X. Wu, and R. A. Dionne, "Upregulation of IL-6, IL-8 and CCL2 gene expression after acute inflammation: correlation to clinical pain," Pain, vol. 142, no. 3, pp. 275-283, 2009.

[222] M. J. Song, Y. Q. Wang, and G. C. Wu, "Additive antihyperalgesia of electroacupuncture and intrathecal antisense oligodeoxynucleotide to interleukin-1 receptor type I on carrageenan-induced inflammatory pain in rats," Brain Research Bulletin, vol. 78, no. 6, pp. 335-341, 2009.

[223] W. Ma and J. C. Eisenach, "Morphological and pharmacological evidence for the role of peripheral prostaglandins in the pathogenesis of neuropathic pain," European Journal of Neuroscience, vol. 15, no. 6, pp. 1037-1047, 2002.

[224] S. H. Zhang, Q. X. Sun, Z. Seltzer et al., "Paracrine-like excitation of low-threshold mechanoceptive C-fibers innervating rat hairy skin is mediated by substance P via NK-1 receptors," Brain Research Bulletin, vol. 75, no. 1, pp. 138-145, 2008.

[225] H. S. Amonoo Kuofi, "The density of muscle spindles in the medial, intermediate and lateral columns of human intrinsic postvertebral muscles," Journal of Anatomy, vol. 136, no. 3, pp. 509-519, 1983.

[226] I. Darian-Smith and P. Kenins, "Innervation density of mechanoreceptive fibres supplying glabrous skin of the monkey's index finger," The Journal of Physiology, vol. 309, pp. 147-155, 1980. 


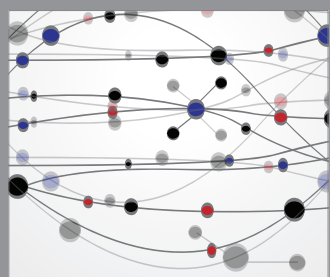

The Scientific World Journal
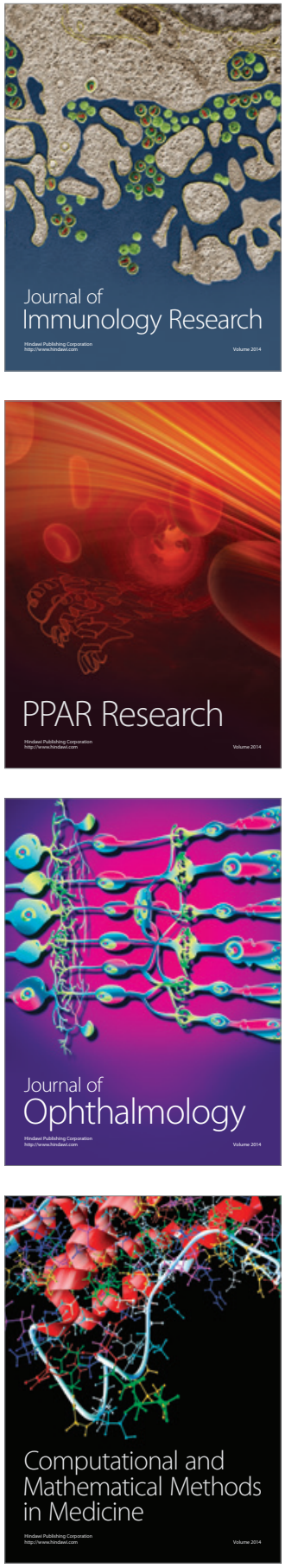

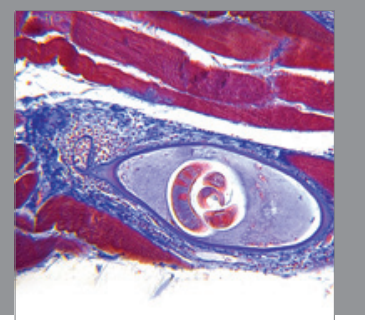

Gastroenterology

Research and Practice
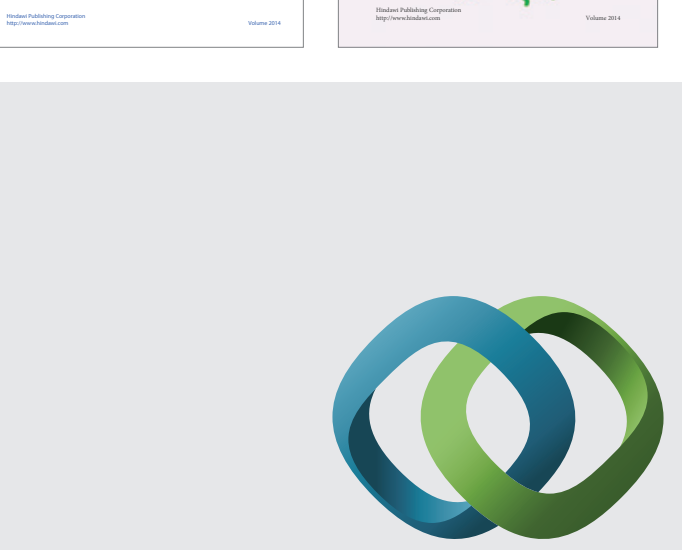

\section{Hindawi}

Submit your manuscripts at

http://www.hindawi.com
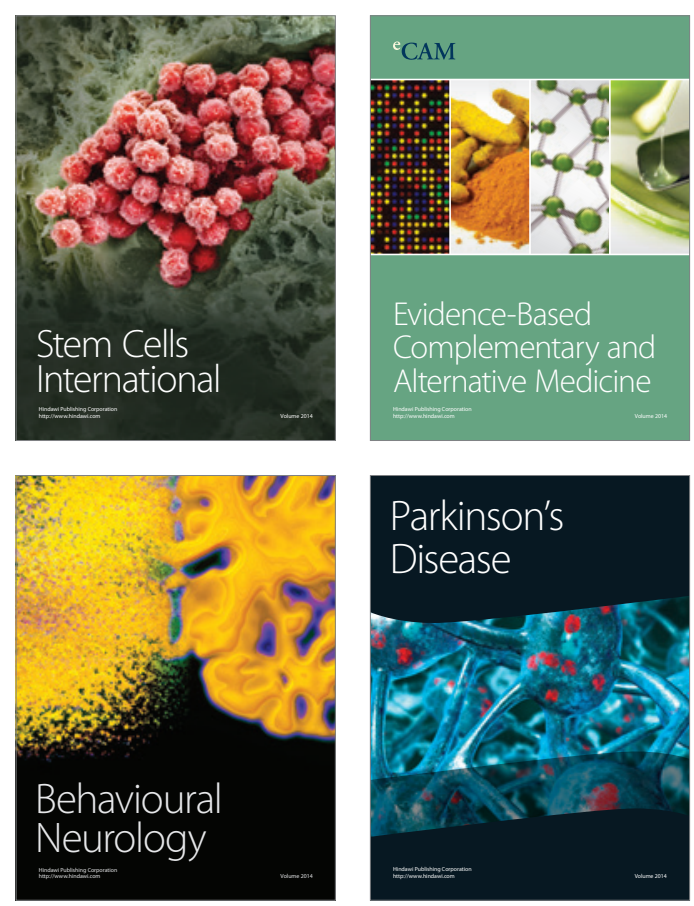

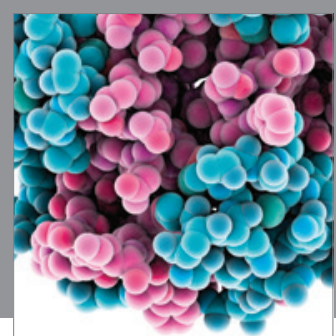

Journal of
Diabetes Research

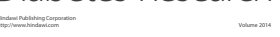

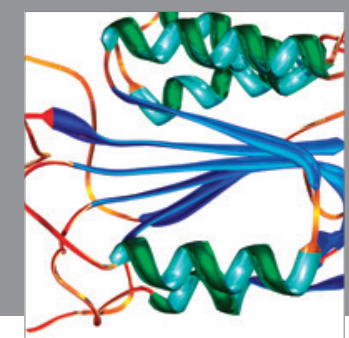

Disease Markers
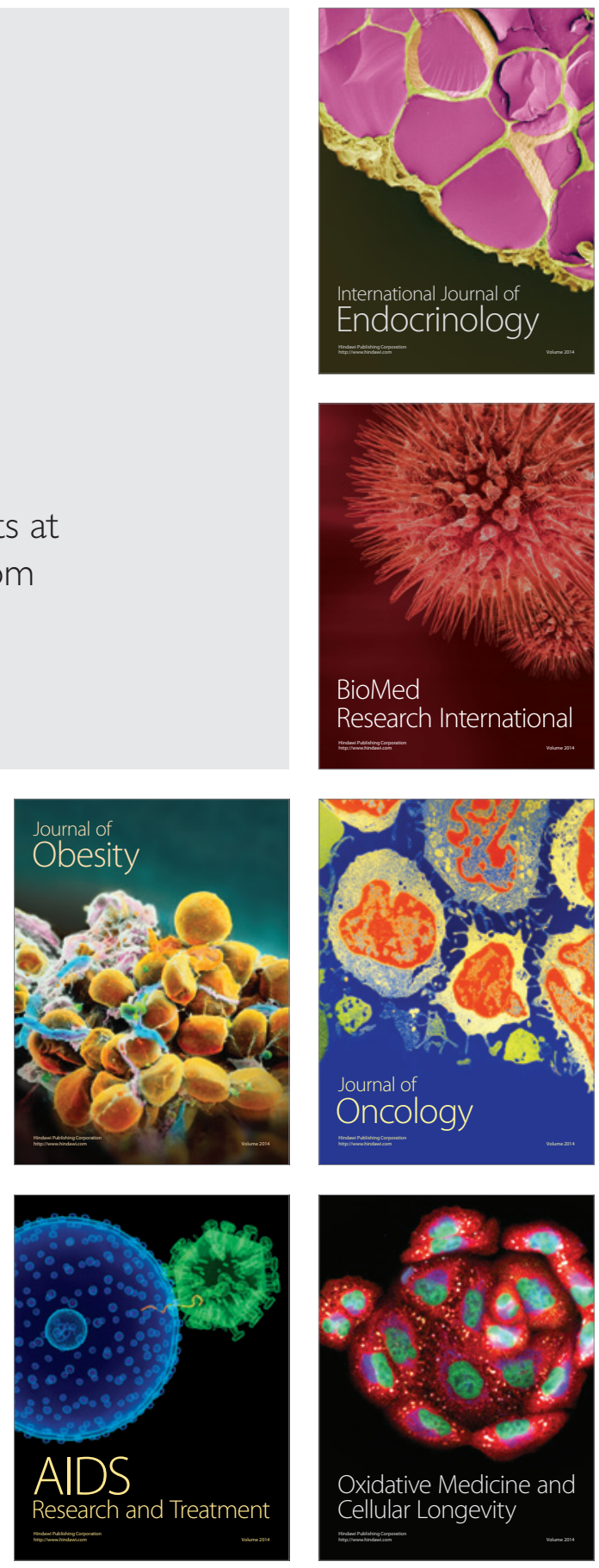